\title{
PSICOLOGÍA Y PSICOTERAPIAS \\ TRANSPERSONALES. \\ REFLEXIONES Y PROPUESTAS
}

\section{TRANSPERSONAL PSYCHOLOGY AND PSYCHOTHERAPIES. REFLEXTIONS AND PROPOSALS}

\author{
Ana Gimeno-Bayón Cobos \\ Instituto Erich Fromm de Psicoterapia Integradora Humanista. Barcelona. España \\ ORCID: https://orcid.org/0000-0001-9479-6721
}

Cómo referenciar este artículo/How to reference this article:

Gimeno-Bayón, A. (2020). Psicología y Psicoterapias Transpersonales. Reflexiones y Propuestas. Revista de Psicoterapia, 31(117), 5-41. https://doi.org/10.33898/rdp.v31i117.446

\begin{abstract}
Resumen
La Psicología Transpersonal ocupa en nuestro país un lugar muy poco conocido. Los estudios académicos han descuidado, por el momento, incluir en la formación profesional de los psicólogos los aspectos relacionados con la dimensión espiritual del ser humano. De este modo, cuando en la práctica clínica se plantean problemas psicológicos relacionados con este ámbito, el profesional se encuentra sin marco teórico o herramientas prácticas para abordarlo. Igual ocurre con los estados de conciencia no habituales, conocidos como Estados Modificados de Conciencia (EMC). Sin embargo, eso no quita que las personas que se encuentran con ellos acudan a un psicólogo algunas veces. Otras lo hacen a un maestro espiritual o a un pseudoprofesional. El presente artículo plantea el panorama general que ofrece la Psicología Transpersonal y los modelos psicoterapéuticos derivados de ella, haciendo hincapié en los elementos comunes y diferenciadores respecto a la Psicología de la Religión, así como las dificultades y carencias que muestran. En él también se hace una propuesta concreta desde el modelo de Psicoterapia Integradora Humanista y se realiza una interpelación a las instituciones académicas y cientificas para que no dejen de incluir en sus estudios e investigaciones los aspectos tratados por la Psicología Transpersonal.

Palabras clave: Psicología Transpersonal, Espiritualidad, Estados Modificados de Conciencia, Psicoterapia Transpersonal, Psicoterapia Integradora Humanista.
\end{abstract}

\begin{abstract}
Transpersonal Psychology occupies a very little known place in our country. Academic studies have neglected, for the moment, to include aspects related to the spiritual dimension of the human being in the professional training of psychologists, so that when psychological problems related to this area arise in clinical practice, the professional finds himself no theoretical framework or practical tools to address it. The same occurs with non-habitual states of consciousness, known as Modified States of Consciousness (CME). However, that does not mean that people who are with problems of this type, can request psychological help. Others do it to a spiritual master or a pseudo-professional. This article presents the general panorama offered by Transpersonal Psychology and the psychotherapeutic models derived from it, emphasizing the common and differentiating elements with respect to the Psychology of Religion, as well as the difficulties and deficiencies that they show. A concrete proposal is also made from the model of Integrative Humanistic Psychotherapy as well as an interpellation to academic and scientific institutions so that they do not stop including in their studies and research the aspects treated by Transpersonal Psychology.

Keywords: Transpersonal Psychology, spirituality, modified states of conciousness, transpersonal psychotherapies, Integrative Humanistic Psychotherapy.
\end{abstract}

\footnotetext{
Fecha de recepción: 4 de septiembre de 2020. Fecha de aceptación: 17 de septiembre de 2020.

Correspondencia sobre este artículo:

E-mail: agimenobayoncobos@gmail.com

Dirección postal: c. Madrazo 113, entresuelo. 2a 08021 Barcelona. España

(C) 2020 Revista de Psicoterapia
}

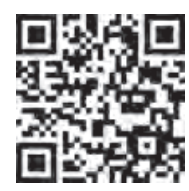


En 1971 un libro titulado No Boundary: Eastern and Western Approaches to Personal Growth (que entre nosotros se tradujo como La conciencia sin fronteras) planteaba una cuestión que se podría sintetizar de la siguiente forma: su autor, Wilber, entiende que hay una modalidad de percepción en la que se experimenta una conciencia unitiva, que constituye el núcleo central de toda religión, y que está inscrita en todos los seres sensibles, pero "paulatinamente vamos limitando nuestro mundo y nos apartamos de nuestra verdadera naturaleza al establecer fronteras. Entonces nuestra conciencia, originariamente pura y unitiva, funciona en diferentes niveles, con diferentes identidades y límites distintos” (Wilber, 1985, p. 11). Esa afirmación, de tinte filosófico y realizada desde la concepción de la realidad advaita (no-dual) que el autor profesa, le va a llevar a realizar interesantes planteamientos a la Psicología.

Entiende Wilber varios niveles del espectro de la conciencia, que van desde los más limitados (nivel de la persona) y pasando por otros más amplios (nivel del ego y nivel del organismo total) hasta el más abarcativo, el de la conciencia de unidad. Pues bien, el autor señala cómo los diferentes modelos de Psicología se han ido limitando a algunos de esos niveles. Así:

a) El Counselling y la terapia de apoyo se quedan en el primer nivel; Psicoanálisis, Psicodrama, Análisis Transaccional, Terapia de Realidad y Psicología del Ego, llegan hasta el segundo nivel (nivel del Ego), mientras que el Análisis Bioenergético, la Psicoterapia de la Gestalt, la Logoterapia, la Terapia de Rogers, la Psicología Humanista y el Análisis Existencial abarcan hasta el nivel del organismo total.

b) Más allá de estos niveles sitúa lo que el llama "bandas transpersonales", en las que coloca a la Psicología Analítica Jungiana, la Psicosíntesis y los estudios de Maslow y Progroff.

c) Respecto al estudio del último nivel, el de la conciencia unitiva, Wilber lo sustrae al ámbito de la Psicología y lo deja en manos de diferentes religiones (Hinduismo vedanta, Budismo Mahayana y Vajrayana, Taoísmo, Islamismo esotérico, Cristianismo esotérico y Judaísmo esotérico).

Dejando de lado, por ahora, los diferentes cuestionamientos a esta clasificación $\mathrm{y}$ a las imprecisiones en que incurre, hay que rescatar las preguntas que la misma provoca o debería provocar a los profesionales de la Psicología: ¿tiene que renunciar esta ciencia al estudio de determinados aspectos psicológicos, cuando estos se relacionen con un determinado tipo o nivel de conciencia?, ¿tiene que renunciar la psicoterapia a discernir cuándo estos tipos de conciencia son sanos o patológicos y abordar el tratamiento de estos últimos?, ¿en base a qué limitaciones autoimpuestas?, ¿qué disciplina es la llamada a ocuparse científicamente de estos temas?

Estas preguntas no son sino la continuación de una larga reflexión histórica: William James, el padre de los psicólogos norteamericanos, insistió una y otra vez en que "nuestra conciencia normal de vigilia no es más que un tipo especial de conciencia, en tanto que, en derredor de ella, y separadas por la más tenue de las pantallas, se extienden formas de conciencia totalmente 
diferentes”. Es como si nuestra percepción habitual de la realidad no fuera más que una isla insignificante, rodeada de un vasto océano de conciencia, insospechado y sin cartografiar, cuyas olas se estrellan continuadamente contra los arrecifes que ha erigido a modo de barreras nuestra percepción cotidiana... hasta que, espontáneamente, las rompen e inundan esa isla con el conocimiento de un nuevo mundo de conciencia, tan vasto como inexplorado, pero intensamente real. (Wilber, 1985 p. 9s.)

No en vano acude Wilber a citar a William James. Cuando este -durante los años 1901 y 1902- dictó en la Universidad de Edimburgo las llamadas "Lecciones Gifford" (que luego se reunirían en el libro que se tituló "Las variedades de la experiencia religiosa", The Varieties of Religious Experiencies), insinuando la desidia, desde la Psicología, para el estudio científico los fenómenos que allí abordaba, estaba lanzando un guante a esta disciplina. Este guante lo recogieron, por un lado, la Psicología de la Religión y, por otro, la Psicología Transpersonal. Algo cambió, a raíz de esas conferencias.

\section{Dos Ramas que se Entrecruzan}

\section{La Psicología de la Religión}

Respecto a la primera, algo cambió, y no porque faltaran estudios de psicología de la religiosidad, sino porque, como apunta Mankeliunas:

Hasta 1900 la psicología de la religiosidad buscaba sus materiales en el pasado, es decir, en la historia de las religiones. De allá sacaba sus materiales, analizaba sus manifestaciones y generalizaba para llegar a las conclusiones generales. Pero desde aquellos tiempos la psicología de la religiosidad viró hacia la religiosidad presente, pues empezó a tomar sus materiales de la actualidad; procedió de la misma manera como proceden las demás disciplinas psicológicas, porque la psicología hoy en día no busca sus materiales en la historia, sino que estudia la vida psíquica presente tanto en su estática como en su dinámica. (Mankeliunas, 1957, p. 162)

Es por esa razón por la que se considera (Font, 1999) que la Psicología de la Religión nace con los inicios del siglo XX. Es más, no parece que haya ningún inconveniente en considerar las conferencias de William James entre las primeras reflexiones desde la misma, junto con las de Starbuck, que en 1899 había publicado su obra The psychology of religion: an empirical study of the growth of religious consciousness. En ella mantenía que la religión pertenece al ámbito de la vida afectiva, puesto que la experiencia religiosa utiliza los sentimientos como indicios de la actividad por la cual el sujeto se relaciona con el universo, actividad que tiene lugar en un nivel subconsciente. Entiende Starbuck que en el ámbito de la vivencia religiosa, los sentimientos son fuente de conocimiento directo, tanto como el intelecto, de modo que la afectividad da cuenta de los hechos externos con tanta verdad y realidad como la cognición. 
En 1905, Leuba dejaba constancia del nacimiento de la Psicología de la Religión como disciplina específica con estas palabras: "Durante los últimos años se ha establecido una nueva rama de la psicología: la psicología de la vida religiosa” (Leuba, 1905, p. 482). Para describir tanto su ámbito como los principios que la regían, daba por bueno lo descrito por Flournoy (1901).

Ambos se podrían resumir en la siguiente forma: La Psicología de la Religión, en tanto que ciencia positiva, necesita asumir las premisas características de la misma. $1^{\mathrm{o}}$ No es suficiente -aunque sí constituyen piezas fundamentales- la acumulación de datos proporcionada por múltiples autobiografías religiosas, sino que necesita de la organización sistemática propia de una ciencia, para conseguir una visión de conjunto, mediante la utilización de estadísticas, comparaciones y encuestas. $2^{\circ}$ Se limita al estudio de la vivencia interior en la conciencia del sujeto, tal como este la experimenta. Por tanto, prescinde de los aspectos externos de la misma y de sus aspectos sociales. $3^{\circ}$ Su preocupación predominante "es la verdad puramente científica, no la edificación piadosa o la defensa de una tesis (sea positiva o negativa) de teología o filosofía" (Flournoy, 1903, p. 7).

La Psicología Religiosa, tal como la concibe Flournoy, se inspira en dos principios: $1^{\circ}$ exclusión de la trascendencia, principio en virtud del cual "la psicología se abstiene de todo veredicto sobre el valor objetivo de estos fenómenos y descarta de su seno las discusiones relativas a la posible existencia y naturaleza de un mundo invisible"; $2^{\circ}$ "una interpretación biológica de los hechos religiosos”, terminología que podría inducir a una interpretación biologicista, que queda descartada cuando el autor aclara que se trata:

de un principio positivo y heurístico, en virtud del cual la psicología aborda estos fenómenos como la manifestación de un proceso vital, cuya naturaleza psicofisiológica se esfuerza en determinar, así como sus leyes de crecimiento y desarrollo, las variantes normales y patológicas, su dinamismo consciente o subconsciente y, en general, las relaciones con las otras funciones y su rol en el conjunto de la vida del individuo y, luego, de la especie. (Flournoy, 1903, p. 27)

Si bien, como recogen Spilka et al. (2003), en los inicios del siglo XX había un fuerte interés por la Religión desde la Psicología (y baste pensar en William James, Stanley Hall, Sigmund Freud o Carl G. Jung),

El segundo cuarto del siglo XX vio un rápido declive en el estudio de la religión entre los psicólogos. El conductismo fue indiferente al tema, mientras que los psicoanalistas lo relegaron al campo de la psicopatología. El efecto neto fue que la investigación en esta área permaneció en la periferia de la respetabilidad científica (Spilka et al., 2003, p. IX).

El mismo camino que la religión, y confundida frecuentemente con ella, siguió la espiritualidad, que "fue dejada de lado e ignorada por los psicólogos, que la concebían como algo patológico o como un proceso que podía reducirse a funciones psicológicas, sociales y biológicas subyacentes más básicas” (Salgado- 
Levano, 2016, p. 2).

El tratamiento otorgado a la experiencia religiosa por parte del conductismo y del psicoanálisis, después del interés que había despertado en los inicios del siglo XX, dio como resultado que -como señalan Falb y Pargament (2014)- dentro del campo de la Psicología se polarizasen las actitudes en torno a la religión, vista como una fuerza solo constructiva o solo destructiva. Estos autores dan cuenta de que la investigación en torno a ella y los datos recogidos de la práctica clínica muestran hoy día una panorámica mucho más variada y matizada, constatando que su carácter psicológicamente positivo o negativo "depende en gran medida del tipo de religión y de las formas en que el individuo interactúa con esa religión y la expresa” (Falb y Pargament, 2014, p. 143).

A mediados del siglo pasado, Mankeliunas, define la Psicología de la Religión como "una ciencia empírica que estudia los hechos psíquicos, referida únicamente a los de carácter religioso" (Makeliunas, 1957, p. 155) y reconoce que -al ser una ciencia joven- sus afirmaciones "no forman un todo continuo y bien trabado, en el que haya un orden riguroso y mutua dependencia, sino que hay hechos aislados sobre los cuales se tiende el puente de las hipótesis" y por eso "le falta unión armónica o unidad orgánica” (Mankeliunas, 1957, p. 154). Más tarde se verá si se puede seguir sosteniendo esta afirmación.

En 1976 la APA creó la división 36 Sociedad para la Psicología de la Religión. Pero, a partir de la década de los cincuenta del siglo pasado, se realizaron múltiples investigaciones -buena parte de ellas desde la vertiente médica- sobre la relación entre salud, espiritualidad y religión. Tales estudios han significado una nueva fase en la investigación científica, que permitieron la incorporación del estudio de la espiritualidad al ámbito académico y que surgiera la expresión de "Psicología de la Religión y de la Espiritualidad” (Quiceno y Vinaccia, 2009) con el que ahora se denomina la división 36 de la APA.

Estas ligeras referencias a la Psicología de la Religión, que pudieran pasar por disquisiciones extemporáneas, son relevantes a la hora de compararla con y diferenciarla de la Psicología Transpersonal, ya que hay espacios en los que es posible un solapamiento entre ambas disciplinas.

\section{La Psicología Transpersonal}

William James, en sus conferencias, en las que había rechazado ofrecer una definición única y esencialista de lo que es "religión", dejó claro que iba a ignorar en ellas la vertiente institucional y centrarse en la vertiente más personal de la misma, es decir, aquella en la que "constituyen las disposiciones internas del hombre el centro de interés, su conciencia, sus merecimientos, su impotencia, su incompletud” (James, 1902/1994, p. 17). En esta religión personal, “los actos a los que este género de religión incita no son rituales sino personales” y en ella "El individuo negocia solo, y la organización eclesiástica, con sus sacerdotes y sacramentos y otros intermediarios, se encuentra en posición totalmente se- 
cundaria" (James, 1902/1994, p. 17).

William James - que abogaba por un estudio empírico y científico de la conciencia humana en todas sus variedades- dirigió su estudio a la vivencia espiritual testificada por personas de muy variada afiliación religiosa, y por supuesto incluía la que puede experimentar una persona que no forme parte de una religión institucionalizada. Ese es el caso del psiquiatra ateo Richard M. Bucke, una de cuyas experiencias recogió en sus conferencias. Este psiquiatra, casi simultáneamente a éstas (1901), publicó la obra Cosmic Conciousness. A study in the evolution of the human mind. En ella intentó prolongar la teoría evolutiva de su admirado Comte, para dar cabida a la experiencia mística personal que tuvo en 1972 y que le marcó en forma indeleble en su vida, en su búsqueda y en su obra. Podría considerarse que estos dos autores (James y Buck) son los pioneros de un campo de estudio que luego asumió la Psicología Transpersonal: lo que James denominó "la religión como práctica personal” sin referencia a un grupo institucionalizado.

Nacida como un desarrollo natural de la Psicología Humanista -cuyas características incluían la consideración de la dimensión espiritual del ser humano y la no limitación de la psicoterapia a la "curación” de determinados síndromes o trastornos de la personalidad- la Psicología Transpersonal fue albergada desde 1976 en la división 32 de la APA como una subdivisión de aquella. Es decir, la Psicología de la Religión y la Psicología Transpersonal fueron acogidas en el mismo año en dos divisiones diferentes de la APA. La descripción que hacía de la Psicología Transpersonal uno de sus fundadores, Antohny Sutich, en el primer número del Journal of Transpersonal Psychology (aparecido en 1969) era la siguiente:

La emergente Cuarta Fuerza (la Psicología Transpersonal) está específicamente interesada en el estudio científico y la implementación responsable de las metanecesidades, los valores últimos, la conciencia de unidad, las experiencias cumbre, los valores B, el éxtasis, las experiencias místicas, el Ser, la autorrealización, la esencia, el asombro, el sentido último, la trascendencia del self, el espíritu, la unidad, la conciencia cósmica, los fenómenos trascendentes... y los conceptos, experiencias y actividades relacionados. Esta definición está sujeta a interpretaciones en relación a la consideración y aceptación de sus contenidos como esencialmente naturalistas, teístas, supernaturalistas o cualquier otra clasificación. (Sutich, 1969)

Como puede observarse, se trata de una descripción acumulativa, que reúne en un ramillete las diferentes temáticas que tenían entre sus manos estudiosas el grupo fundador de la Psicología Transpersonal. Junto con Sutich, estaban en él Abraham Maslow y Stanislav Grof.

Maslow había decidido que para una comprensión cabal de la realidad del ser humano, había que contemplarlo a partir de lo que es una persona sana. Por ello, y dentro de esta intención, había dedicado buena parte de su investigación al estudio y sistematización de las características comunes a una serie de experiencias (que él denominó "experiencias cumbre”) testimoniadas por personas psicológicamente 
muy sanas (“autorrealizadas” en su vocabulario), que sobrepasaban "por arriba” tanto el concepto de autorrealización como los criterios habituales de salud mental.

La constatación de este tipo de experiencias en un contexto de equilibrio mental configuró un nuevo territorio a explorar, bien lejano del de la psicopatología en el que habían quedado confinados este tipo de fenómenos. Mas bien, como irónicamente dirá este autor, esta ampliación del mapa del psiquismo, llevaba a pensar que lo hasta entonces considerado "normal" no es otra cosa que "una psicopatología de lo cotidiano”. (Maslow, 1973, p. 16, citado en Gimeno-Bayón, 2015, p. 9)

Comprobaba Maslow que las características de esas experiencias cumbre (conciencia de unidad, trascendencia, asombro, sensación de sentido, eliminación de las dimensiones espacio-temporales, etc.) eran coincidentes con las que describían las vivencias descritas por los místicos religiosos, a propósito de sus éxtasis.

Además, este autor había ido determinando lo que llamó “metanecesidades”, relacionadas con la necesidad de satisfacer los “valores del Ser” para experimentar la autorrealización. Entendía Maslow que, si las necesidades que generan esos valores (entre los que figuran los trascendentales platónicos) no se cubrían, surgirían "metapatologías”, no diagnosticables y abordables a partir de las patologías y psicoterapias convencionales.

Por su parte, Grof, antes de trasladarse en 1967 a Estados Unidos, había estado investigando con LSD durante años en el Psychiatric Research Institute de Praga, y comprobando las posibilidades terapéuticas de esta sustancia, a la hora de inducir estados alterados de conciencia que permitían revivir y reparar antiguos traumas albergados en el inconsciente. Algo que le llamó la atención es que, tras las experiencias psicodélicas, algunas personas iniciaban una búsqueda de tipo espiritual. En su nuevo lugar de residencia siguió trabajando con sustancias psicodélicas. Pero ahora, para paliar las dificultades legales de este trabajo en un país en el que la LSD estaba prohibida, creó un tipo de respiración que podía modificar igualmente la conciencia en un sentido similar al de la esa droga.

Como puede verse, la definición inicial primera de la Psicología Transpersonal era una recopilación de los temas que estaban acaparando la atención investigadora de los iniciadores.

Más allá de la lista que se enumeraba ¿cuál era el común denominador, lo que daba unidad a esta lista? Posiblemente sea el interés en explorar zonas de la conciencia que van más allá de los estados habituales y que se relacionan con las posibilidades más plenas del psiquismo humano. En este sentido, se trataba de aplicar la investigación, desde la Psicología, a esos dominios cuyo tratamiento se atribuía (en el mapa de Wilber que se ha citado) exclusivamente a las religiones.

Ahora bien, si la Psicología Transpersonal se ocupa de esos ámbitos, estudiados desde el punto de vista psicológico, ¿en qué se diferencia de la Psicología de la Religión?, ¿son lo mismo? Si son lo mismo, ¿por qué se encuentran albergadas en dos divisiones diferentes de la APA? Si no son lo mismo, pareciendo que el 
objeto de estudio es el mismo, ¿qué es lo específico de cada una de ellas, o hasta qué punto se solapan?

\section{Unas Borrosas Fronteras}

\section{El Problema de los Términos}

Uno de los problemas para delimitar las fronteras entre las dos disciplinas es definir el ámbito del que una y otra se hace cargo, suponiendo que sean distintos.

Es cierto que la Psicología Transpersonal, como refieren Lajoie y Saphiro (1992), arrastraba desde su nacimiento la dificultad de su definición. Estos autores publicaron una revisión sistemática de 202 citas bibliográficas referentes a la Psicología Transpersonal a lo largo de los veintitrés años siguientes a la definición arriba ofrecida, y encontraron como categorías más recurrentes las siguientes: 1. Estados de conciencia; 2. Máximo o más elevado potencial; 3. Más allá del ego o del yo personal; 4. Trascendencia; 5. Espiritual.

Como resultado de su estudio, y tras presentar 40 definiciones de la Psicología Transpersonal, se decidieron a ofrecer la siguiente, por entender que sintetizaba los aspectos más relevantes de todas las recogidas: "La Psicología Transpersonal se ocupa del estudio del más alto potencial de la humanidad y del reconocimiento, comprensión y realización de estados de conciencia unitivos, espirituales y trascendentes” (Lajoie y Saphiro, 1992, p 91).

Aún cuando la Psicología de la Religión, si bien desde sus inicios (si queremos considerar como tales estos momentos de finales del siglo XIX, con Starbuck e inicios del siglo XX, con Bucke, James, Flournoy y Leuba, entre otros), perfilan con nitidez definitoria su campo de investigación (el descubrimiento de las estructuras psicológicas y factores subyacentes a la actitud y comportamientos religiosos y delimitar lo que en ellos puede haber de sano y de patológico) y su metodología (empírica, con los instrumentos propios de la ciencia psicológica del momento), carecía de una definición delimitativa de lo que se entiende por "religión". El significado plural de este término ha sido objeto de múltiples intentos de concreción. Vergote señala que "Como se sabe, Leuba ya coleccionó cuarenta y ocho definiciones de la religión, a las que él mismo añadió otras dos, posteriormente abandonadas ante la imposibilidad de justificarlas por criterios objetivos" (Vergote, 1969, p. 25) y este autor decide adoptar la formulada por Thouless (1961, pp. 3s.),

"la religión es una relación vivida y practicada con el ser o los seres suprahumanos en los que se cree. La religión, en consecuencia, es un comportamiento y un sistema de creencias y de sentimientos”. En nuestra opinión los "sentimientos religiosos", las "experiencias religiosas", los ritos, las creencias, son fenómenos parciales. No negamos la posibilidad de una actitud religiosa individual, inexpresada a través de un rito socializado, del mismo modo que concebimos sin dificultad que un sujeto religioso pueda realizar ritos religiosos sin adherirse interiormente a su sentido propiamente 
cultual, pero tanto desde el punto de vista subjetivo del hombre religioso, como desde el punto de vista objetivo de las religiones existentes, creemos, que solamente la realidad compleja, compuesta de creencias, de praxis y de sentimientos orientados, realiza la intencionalidad religiosa. (Vergote, 1969, p. 24)

Por su parte, Salgado-Levano, tras ofrecer otras definiciones de autores más actuales, y constatar las diferencias entre las mismas, acaba señalando que:

hay un hilo conductor, entendido como el conjunto de prácticas, creencias, rituales, símbolos que se viven a nivel institucional y que tienen como base la relación con Dios, el modo como se le percibe y qué actitudes se tienen frente a Él, de ahí dependerá la asunción del estilo religioso que se viva, basado solo en lo superficial, entendido como el mero cumplimiento de normas y prácticas propias de una religión, o como la manifestación coherente de una relación profunda de amor a Dios, que se alimenta por el amor que proviene de Él y la fe que suscita. (Salgado-Levano, 2016, p, 3s)

Claro está que la definición de Salgado-Levano se restringe al ámbito de las religiones teístas, cosa comprensible, teniendo en cuenta que la Psicología de la Religión surge en un contexto sociológico en el que las religiones ateas (que no el ateísmo) o agnósticas no habían penetrado masivamente en la sociedad.

Para Koenig et al. (2001) la espiritualidad es la búsqueda personal para entender las respuestas a las últimas preguntas sobre la vida, su significado, y la relación con lo sagrado o lo transcendente, que puede o no conducir al desarrollo de rituales religiosos y la formación de una comunidad, mientras que la religión es un sistema organizado de creencias, prácticas, rituales, y símbolos diseñados para facilitar la cercanía a lo sagrado o transcendente (Dios, un poder más alto, o la verdad o la realidad última). (Quiceno y Vinaccia, 2009, p. 323)

Una de las concepciones sobre el término que parece haber tenido más aceptación es la que proponen Beit-Hallahmi y Argyle (1997), que entienden la religión como una actitud que integra tres dimensiones: las creencias religiosas (dimensión cognitiva), los comportamientos religiosos y rituales más o menos pautados (dimensión comportamental) y la vinculación del sujeto con la trascendencia (dimensión afectiva).

Para estos autores, la religión no se reduce a una actitud individual vivida en la intimidad de la conciencia, aún cuando reconozcan la relevancia de estas experiencias: La experiencia solitaria marca también los testimonios de grandes revelaciones y el éxtasis de los grandes místicos. Estos milagros privados constituyen lo que llamamos la experiencia religiosa [...]. Las conversiones parecen como otro tipo de milagro, iniciaciones imprevistas entre la certeza de las viejas o las nuevas creencias. Pero tanto las experiencias religiosas como las conversiones son en última instancia sociales en sus fuentes y consecuencias. (Beit-Hallahmi y Argyle, 1997, p. 4) 
Aún así, hay autores que no comparten una visión de la religión que consideran restrictiva, al menos en relación a lo que afecta al objeto de la Psicología de la Religión, como mostró William James. Es más, algunos -como Frankl- afirman que "ser religioso significa plantearse apasionadamente la pregunta del sentido de nuestra existencia” (Frankl, 2003. p.114). En este sentido, desaparecen dos de las dimensiones de la concepción de Beit-Hallami y Argyle: las creencias (transformadas en preguntas), y los comportamientos cúlticos y rituales. E incluso, para algunos, como ocurre con Aranguren, tal como se expresa en el prólogo en castellano a la obra de James, la dimensión afectiva:

Homo religiosus, en sentido amplio, es todo el que toma en serio el mundo y la vida; por tanto, también, según James, el ateo que lo es con seriedad. La expresión religiosa es, dice el autor, “solamente” siempre. Y el ateo se diferencia del religioso en que carece del "sentimiento" de esa "experiencia”. (Aranguren, 1994, p. 3)

Como puede suponerse, un concepto de religión un tanto "líquido" (que diría Bauman), hace difícil precisar el campo de investigación de la Psicología de la Religión. Más aún cuando a la misma se añade el concepto de "espiritualidad”. ¿Qué se entiende bajo ese término?

De acuerdo con Piedmont (2004) la espiritualidad puede ser definida como una motivación intrínseca que conduce a las personas a construir un significado personal para la vida dentro de un contexto escatológico, es decir, del destino del hombre luego de la muerte. Por su parte, para el autor la religiosidad se define como un sentimiento, término clásico en psicología que refleja tendencias emocionales que se desarrollan a partir de las tradiciones sociales y experiencias educativas (Ruckmick, 1920; Woodworth, 1940). (Simkin, 2017a, p. 180)

Pero el concepto de espiritualidad es tan o más escurridizo que el concepto de "religión".

Koenig, en un análisis del recorrido que ha atravesado el concepto de "espiritualidad”, señala cómo ha ido cambiando lo que se alojaba en el interior del mismo: "Tradicionalmente, la espiritualidad se usaba para describir a la persona profundamente religiosa, pero ahora se ha expandido para incluir a la persona superficialmente religiosa, el buscador religioso, el buscador del bienestar y la felicidad y la persona completamente secular” (Koenig, 2008, p. 349). Concluye este autor: "O la espiritualidad debe definirse y medirse en términos tradicionales como una construcción única y no contaminada, o debe eliminarse de su uso en la investigación académica” (Koenig, 2008, p. 349).

Es lógico, entonces, que Simkin se queje de que, a pesar del interés que ha mostrado la Psicología de la Religión desde sus inicios por el estudio de la religiosidad y la espiritualidad, y del incremento de ese interés en los últimos años, "la falta de consenso en cuanto a su definición ha contribuido a una proliferación de instrumentos de evaluación disímiles, dificultando la integración sistemática de los 
resultados reportados en los distintos estudios (Hill, 2012)"(Simkin, 2017a, p. 178). Beca Infante intenta deslindar la religiosidad y la espiritualidad, pero reconoce la variedad de contenidos que se agrupan bajo esta última:

Lo espiritual se refiere al mundo de los valores, a la posición personal ante lo trascendente y sobre el sentido último de las cosas, a la visión global de la vida y de las opciones personales. La religión en cambio es un conjunto de creencias y concepciones sobre lo trascendente, junto a prácticas y ritos compartidos con una comunidad de creyentes. Si bien no todas las personas tienen una religión, todas tienen, de alguna manera, inquietudes espirituales y éstas aumentan en situaciones especiales como la enfermedad. [...] Se han referido más de 90 intentos de definición de espiritualidad, las que incluyen conceptos tan variados como la relación con Dios o un ser espiritual, algo superior a uno mismo, trascendencia, significados y fines de la vida, fuerza vital de la persona, vida interior, paz interior, comunión con otros, contacto con la naturaleza, relaciones con familiares y amigos, etc. Así la espiritualidad se refiere al conjunto de aspiraciones, convicciones, valores y creencias que permiten a cada persona orientar sus proyectos de vida. Incluye necesariamente lo religioso, pero no se agota en ello, aunque para muchas personas su espiritualidad es religiosa en cuanto a que a través de su fe buscan respuestas acerca de lo sobrenatural y llegan a establecer una relación con Dios y la trascendencia. (Beca Infante, 2008)

Mas, a pesar de estos intentos de diferenciación, si la religión la entendemos entonces, en una acepción amplia -como hacían Frankl y Aranguren- como el conjunto de experiencias que se relacionan con el sentido último de la vida, difícilmente se va a poder mantener la frontera entre los dos constructos. La realidad es que ambos pueden ir juntos o separados en la experiencia de los diferentes sujetos. Krishnakumar y Neck (2002), después de revisar las definiciones que se ofrecen sobre la espiritualidad, concluyen que se pueden sintetizar agrupándolas desde tres perspectivas:

a) una perspectiva intrínseca: en ella, la espiritualidad se origina en la interioridad del individuo y es capaz de trascender las normas religiosas. Hace referencia al sentimiento de conexión con la esencia de uno mismo, los demás y el conjunto del universo.

b) una perspectiva religiosa: en esta, por el contrario, se asumen las creencias en entidades sobrenaturales o poderes impersonales que rigen el universo, según una religión concreta, así como sus propuestas morales.

c) una perspectiva existencial, que pone el acento en la búsqueda del sentido de la propia actividad y la propia vida.

Eso sí, como indica Salgado-Levano:

Indudablemente, se pueden encontrar definiciones que con claridad aborden una de las perspectivas, pero también se van a encontrar definiciones que integren dos o tres perspectivas ya que, por ejemplo, podría existir la 
espiritualidad cuya base es religiosa, pero se asienta en un origen intrínseco y tiene implicancias a nivel existencial. (Salgado-Levano, 2016, p. 10)

Más allá de las diferentes descripciones para diferenciar religiosidad y espiritualidad, y de la general admisión de la posibilidad de una espiritualidad no religiosa, es relevante la repetitiva consideración que hacen distintos autores a la hora de vincular la primera a la esfera afectiva, mientras desvinculan de ella a la espiritualidad. Ya se vio que así lo hacía Starbuck, y, como señala Simkin (2017b), así lo harán Piedmont (2004a) Ruckmick (1920) y Woodworth (1940). Aranguren, resumiendo el pensamiento de William James al respecto, señalaba: "el ateo se diferencia del religioso en que carece del 'sentimiento' de esa 'experiencia' ” (Aranguren, 1994, p. 3).

Aún complica más la situación el hecho del dinamismo de los constructos. Koenig (2008) señaló cómo el concepto de “espiritualidad” había ido evolucionando desde una versión tradicional en la que la espiritualidad se hallaba profundamente vinculada a la vivencia religiosa, a una versión moderna, en la que se concebía la posibilidad de personas espirituales, pero no religiosas, hasta llegar a una concepción de la espiritualidad que abarca también a la persona con una cosmovisión agnóstica $o$ atea.

\section{Ámbito de Coincidencia y Caminos Divergentes}

Ya se ha podido ver, por lo expuesto hasta ahora, que:

a) por un lado, la Psicología de la Religión se ocupa, al menos parte de ella, de la dimensión psicológica de la espiritualidad (sin perjuicio de las dificultades de definición de tal constructo); y

b) por otro, la Psicología Transpersonal incluyó, ya desde su nacimiento, constructos con claras raíces o connotaciones religiosas (éxtasis, experiencias místicas, fenómenos trascendentes), junto con otros del ámbito de la espiritualidad (espíritu, sentido último, trascendencia del self). Eso sí, no hay referencia alguna a que esos fenómenos guarden alguna relación con la vivencia religiosa, ni siquiera en el sentido acuñado por James de "religión personal". En la misma línea va la definición sintética de Lajoie y Saphiro que antes se citó: los estados de conciencia unitivos, espirituales y trascendentes son campo de estudio de la Psicología de la Religión explícitamente, e implícitamente también lo es "el estudio del más alto potencial de la humanidad”, que luego cada religión determinará con una categoría propia (santidad, iluminación, etc.).

Se podría pensar que la coincidencia del enfoque psicológico (sabiendo que se hará desde las distintas escuelas o corrientes que conviven en él) y la coincidencia en buena parte del ámbito a tratar (con áreas de ambas disciplinas que claramente se solapan), hay bastantes estudios e investigaciones que pueden insertarse en cualquiera de las dos. Probablemente la adscripción a una u otra por parte de sus editores, lectores y círculos de difusión, va a depender más del sentido de pertenencia de sus autores que del tema en sí. 
Pero conviene también hacer notar que entre ellas hay diferencias-sutiles o no tan sutiles- que les dan un colorido propio e irreductible. Hay algunas diferencias palpables, pero, en conjunto, se trata más de cuestión del énfasis que cada una de ellas pone en determinados aspectos, de gradación, que de discrepancia académica o científica. Sin embargo, ese diferenciado aroma es intuitivamente perceptible y generador de una reacción afectiva de atracción o rechazo por parte de las personas que se acercan a una u otra. Veamos esas divergencias:

El Paritorio. Si se simplifica, se podría decir que una nace en una clínica, con métodos convencionales, y la otra de parto natural, en casa.

Ambas disciplinas se gestan en contextos sociológicos bien diferenciados. La que después sería la división 36 de la APA (Psicología de la Religión) se desarrolló a partir de la iniciativa de un núcleo de psicólogos católicos la American Catholic Psychological Association (ACPA) (véase en Reuder, 1999), si bien luego fue desbordando esos límites y ampliándose tanto en lo que se refiere a la adscripción religiosa de sus miembros como en lo que se refiere a la inclusión de la espiritualidad. Los padres, pues, formaban parte de una religión institucionalizada. El contexto en el que nació la Psicología Transpersonal era el propio de la contracultura californiana de los años sesenta, en el que imperaban el sincretismo y lo que se ha llamado "religión a la carta”, pero sobre todo "la religión de la no religión” (Peter Watson, 2014). Este autor afirma: "En Esalen todo el mundo profesa sus dogmas con moderación, definiéndose a sí mismos como personas '¿espirituales pero no religiosas... En este lugar el misticismo no es una suerte de abstracción trascendente, carente de todo contenido político o moral'” (Watson, p. 559). También hay un detalle importante a tener en cuenta: en el nacimiento de la Psicología de la Religión hay todo un equipo de expertos que aportan sus conocimientos (los pioneros y predecesores como Starbuck, Bucke, Flournoy, James, Assagioli, Jung, Allport, etc.). El nacimiento de la Psicología Transpersonal tiene lugar en la intimidad de la familia que lo da a luz. Aunque los padres conocen las aportaciones de estos pioneros, parecen prescindir de ellas y arreglárselas con los medios exclusivos de lo que ellos están investigando. Baste ver la diferencia entre las citas a la literatura anterior por parte de unos y de otros.

Los Destinatarios. Por el propio marco en que nacieron, mientras la Psicología de la Religión dirigió su atención, ante todo, al estudio de los hechos psíquicos de carácter religioso en personas mayoritariamente encuadradas en un marco religioso tradicional, básicamente occidental -en un principio- y teísta, la Psicología Transpersonal asumió el estudio de los hechos psíquicos de carácter religioso -o espiritual- de personas alérgicas a la institucionalización de casi todo, y más bien dentro de un marco no teísta y muy influido por la religiosidad oriental.

Es más: si eso era así en el momento en que surgió la Psicología Transpersonal, no se puede obviar que, entre nosotros, la evolución social ha llevado a buena parte de las personas, jóvenes y adultos jóvenes, a crear su propio marco de espiritualidad (religiosa o no, y muchas veces sincrética) no exento de ignorancia y 
contradicciones. En el instituto en el que la autora de este escrito ejerce su profesión, se suele entregar a los solicitantes de psicoterapia un cuestionario inicial en el que se incluye la pregunta por la cosmovisión en la que preferentemente se sitúan. Lo habitual es que no elijan una sola, sino que marquen varias a la vez como "postura principal” y no es nada infrecuente que señalen como tal, simultáneamente, el ateísmo, el teísmo y el panteísmo. En cambio, es una muy pequeña minoría las que señalan religiones institucionalizadas (cristianismo, judaísmo, budismo, hinduismo o islam) de una lista de quince opciones. Un pequeño grupo marca como postura principal el esoterismo y algunos marcan "otros", por no sentirse identificados con ninguna de las opciones presentadas. A la vez que ello, se ha podido constatar un aumento claro de indiferentismo o banalización respecto a esta cuestión, mucho menos relevante hoy que hace treinta años, como se deduce de las respuestas que dan en dicho cuestionario a la aspiración a tener una visión filosófica o religiosa unificadora sobre el sentido de la vida, del ser humano, del mundo, etc.

Conviene subrayar que el nacimiento de la Psicología Transpersonal estuvo muy marcado por la apología de las “experiencias cumbre” descritas por Maslow. Señala Peter Watson que "No es posible basar la existencia exclusivamente en este tipo de vivencias, pero Maslow hacía hincapié en que, lo contrario, una vida sin ellas, resultaría enfermiza, nihilista y potencialmente violenta” (Watson, 2014, p. 561). Muchos jóvenes de la contracultura californiana de los años sesenta, pacifistas, curiosos, arriesgados, y a veces banales y poco pacientes, se lanzaban a explorar cómo provocarse este tipo de experiencias. Bien lejos de la religiosidad del esfuerzo y el compromiso cognitivo e institucional que marcaba el estilo de los grupos en los que se gestaba la Psicología de la Religión.

Los Límites. La Psicología de la Religión y de la Espiritualidad reduce su campo a la exploración de la dimensión psicológica de estos fenómenos. La Psicología Transpersonal, no. No hay que olvidar que uno de los fundadores, Grof, llevaba investigando con drogas psicodélicas desde los años 50 del pasado siglo y que en el primer ambiente que la acogió abundaba el consumo de las mismas. El estudio de lo que se llamó "estados alterados de conciencia" o "estados modificados de conciencia” provocados por ese consumo, formó parte del objeto de estudio de la Psicología Transpersonal y, por extensión, los estados de conciencia no habituales, sea por la realización de alguna práctica dirigida a conseguirlos (prácticas regresivas a través de respiración holotrópica, de sonidos de percusión, o de aislamiento sensorial, etc.) sea por darse en forma espontánea. Si bien la Psicología de la Religión y la Espiritualidad abordaban los estados alterados que se producían como consecuencia de una experiencia de tipo religioso-místico (éxtasis) no abordaba este otro tipo de fenómenos. Parte de la Psicología Transpersonal se centró en el estudio de estados de conciencia no habituales, tanto dentro del marco de lo religioso-espiritual como fuera de él. Sirva como ejemplo la cartografía de estados de conciencia que señala Krippner (1979) en la que distingue veinte modalidades diferentes, o la de Weil (1997), relacionando el tipo de ondas cerebrales y los chakras del hinduismo. Grof 
(2015) describe 44 experiencias que incluye como transpersonales, entre las que se encuentran fenómenos tan variados como la identificación con animales, vivencias filogenéticas, vivencias espiritistas, conciencia cósmica, vivencia del ADN o de encarnaciones pasadas.

El Método. Ya se señaló que uno de los dos principios que había marcado Flournoy para la Psicología de la Religión fue "la exclusión de la trascendencia”, es decir, que (al igual que recalcó reiteradamente William James) el estudio de la disciplina se restringe a la dimensión interior, al psiquismo de la vivencia religiosa y/o espiritual. A indagar, por tanto, aspectos motivacionales que respondan a preguntas del estilo de las que plantean Beit-Hallahmi y Argyle (1997): ¿por qué hay personas que participan en actos religiosos? ¿hay diferencias, en términos de personalidad, que caracterizan a los sujetos de un alto nivel de religiosidad (o espiritualidad)? ¿qué consecuencias tiene tal actitud en la vida de esas personas? ¿hay motivos ocultos en esa actitud? Como señalan estos autores, "la psicología de la religión es, por definición, empírica. Ofrece observaciones y explicaciones de los fenómenos de la religión, utilizando la terminología de las teorías psicológicas” (Beit-Hallahmi y Argyle, 1997, pp. 8).

Esta exclusión de la trascendencia llevó a los estudiosos de la Psicología de la Religión a plantearse bien pronto qué postura era la más adecuada para estudiar el tema. Mankeliunas (1957) resume tres posturas: a) la de los que consideran que será más científica la postura del empírico arreligioso; b) la de quienes piensan que el psicólogo religioso comprenderá mejor los fenómenos a estudiar. Esta es la postura mantenida mayoritariamente por el Congreso de Psicología de la Religión celebrado en Lancaster de 1977, en el que se entendía que el psicólogo agnóstico $\mathrm{o}$ ateo "deben atenerse a la búsqueda de correlaciones superficiales entre medidas de religiosidad y otras variables externas" (Garcés, 1985, p. 190); y c) la que quienes sostienen que el ideal es que el estudioso haya sido religioso (que le permitirá entender lo que está tratando) y haya abandonado la religión (que le permitirá ser más imparcial). Las posturas radicales han ido dejando paso a propugnar, como apuntan Mankeliunas (1957) y Vergote (1969) lo que este último denomina "una neutralidad benevolente", es decir, un rigor que no excluya un interés y una cierta simpatía por el tema que estudia, como se exige a cualquier científico respecto a lo que investiga.

Pues bien: no queda más remedio que constatar que, así como los psicólogos de la religión han sido escrupulosos en mantener el principio de exclusión de la trascendencia, aunque estudien los fenómenos religiosos inscritos en una religión particular, los psicólogos transpersonales no lo han sido tanto. Sorprende que no hayan seguido el impecable camino marcado por algunos pioneros, como Assagioli (1973; 1993a). Demasiado frecuentemente han atribuido un valor objetivo a los fenómenos de conciencia narrados por los sujetos investigados o han elaborado sus teorías a partir de su postura religiosa/espiritual. Y hay que decir que, cuando eso ocurre, están confundiendo el "hacer psicología" con "hacer filosofía" o 
"hacer teología” (si es que es posible decir esto último en relación con religiones ateas). Un ejemplo: Wilber, acaso el más conocido y prolífico de los autores que figuran en cualquier lista de Psicología Transpersonal, capaz de reinventarse a sí mismo unas cuantas veces, puede pasar de realizar relevantes aportaciones a la Psicología -como la que se nombrará después- a determinar qué cosmovisiones son "más verdaderas" o "superiores" a las otras, o la afirmar como hecho la caída de la divinidad que sostienen algunos hinduismos (Wilber, 1998). Otro ejemplo es el de los autores que incurren en lo que Heron (2006) denomina "la falacia de la reencarnación”. Así, Grof (1988) pasa de narrar las experiencias de los sujetos de sus investigaciones a dar por válido como hecho objetivo el contenido de las mismas, elevando a la categoría de realidad empírica las reencarnaciones anteriores del sujeto, etc. Igual hacen autores como Boadella (1993) que, tras un riguroso estudio de la formación de la personalidad en base al desarrollo embrionario, pasa a formular como incontestable la reencarnación post-mortem. Bastante lejos de lo que Scharrón del Río pide, cuando señala que "La rigurosidad, la asepsia, y el método científico, son instancias que requieren del ejercicio de disciplina en la ciencia” (Scharrón del Río, 2010, p.89).

La Vocación. Mientras la Psicología de la Religión se ha centrado, básicamente, en la comprensión de los fenómenos religiosos y espirituales, la Psicología Transpersonal nació desde y para la psicoterapia. La comprensión de la dimensión trascendente está al servicio del cambio, la sanación y el crecimiento. Son escasos los tratadistas de Psicología de la Religión que -como Garrigou-Lagrange (1957), para el cristianismo- han creado un estudio sistemático de la espiritualidad, diferenciando entre espiritualidad sana e insana y señalado pautas a seguir ante los problemas que esta última plantea.

La Psicología Transpersonal -aparte del importante modelo pionero de la Psicosíntesis de Assagioli (Assagioli, 1973; 1993a; 1993b)- ha dado también lugar a lo que Grof (2015) denomina “la gran cartografía de la psique humana” elaborada a partir de sus investigaciones, y en la que explora más allá del nivel biográfico habitual lo que el llama "niveles transbiográficos", relacionando las experiencias perinatales del trauma del nacimiento con experiencias espirituales, señalando la jerarquía de las diferentes constelaciones inconscientes y su dinámica específica. Estas investigaciones han servido a Stanislav Grof para elaborar, junto con su esposa Christine, métodos específicos de tratamiento de las crisis y emergencias espirituales (Grof y Grof, 1993a; 1993b; 1993c; 1994). Ha dado lugar a un modelo de corte psicoanalítico (Washburn, 1990, 1997, 1999) para orientar las crisis regresivas hacia la curación mediante la recuperación de la dimensión trascendente, o a modelos como el de Nelson (2000) para tratar las patologías psiquiátricas relacionadas con la espiritualidad, y a estudios diagnósticos de salud e insania mental en la religiosidad (McNamara, 1979), al igual que ha hecho Wilber (1985; 1994a; 1994b; 1994c), o la propia autora de este escrito (Gimeno-Bayón, 2019a). O, más que centrarse en las diferentes patologías, han aportado recursos concretos para el desarrollo de la 
dimensión transpersonal (Ferrucci, 1981; Gimeno-Bayón, 2019b; 2020).

\section{Las Carencias de la Psicología Transpersonal}

Como consecuencia de lo anteriormente relatado, la Psicología Transpersonal adolece de una serie de carencias que, enumeradas esquemáticamente se pueden sintetizar en la siguiente forma:

a) Pareciera que la Psicología Transpersonal, al prescindir de las aportaciones anteriores a su nacimiento sobre temas que ella misma toca, quisiera subrayar que se trata de algo ex novo y no necesita apoyarse en nada (actitud un tanto narcisista, por otro lado). Esto tiene la ventaja de partir sin un marco que pueda empañar con prejuicios heredados sus hallazgos, a partir del estudio empírico de lo que directamente constata. Tiene la desventaja de que pierde las aportaciones realizadas por los estudios empíricos que la precedieron y de no aprovechar lo que se llama "cultura”, es decir, el legado de sabiduría que se va heredando de las generaciones anteriores y que nos permite no tener que inventar el fuego y la rueda. Sin embargo, difícilmente se puede exponer una teoría sin que esta se encuentre encuadrada -implícita o explícitamente, consciente o inconscientemente- en el marco de una metateoría. La Psicoterapia Transpersonal, en general, no es una excepción:

Recientemente, Walsh y Vaughan (1993) caracterizaron los estudios transpersonales como disciplinas independientes de cualquier tradición religiosa, escuela filosófica o concepción del mundo. Sin embargo, los fundamentos filosóficos de la teoría transpersonal han sido a menudo asociados con la filosofía perenne (Hutchins, 1987; Rohtberg, 1986; Valle, 1989; Wilber, 1990; 1995), y el pensamiento universalista acerca de la espiritualidad humana característico del perennealismo impregna virtualmente toda la literatura transpersonal contemporánea (véase, por ejemplo, Grof, 1998, 1993; Harman, 1988; Nelson, 1994; Vaughan, 1986, 1988; Wittine, 1989). (Noguera Ferrer, 1999, p. 72)

Eso significa que al prescindir (teóricamente) del apoyo cultural externo, frecuentemente han creado para algunas de sus afirmaciones un sustrato filosófico que, como se dijo en otro lugar,

les ha llevado a practicar un amateurismo filosófico, ser poco sensibles a los diferentes paradigmas que se han ido sucediendo en aquella ciencia, $\mathrm{y}$, en definitiva, ser poco rigurosos a la hora de elaborar un pensamiento multidisciplinar. No ha sido, a mi juicio, hasta la obra de Ferrer (Noguera Ferrer, 1999; Ferrer, 2003), donde se ha planteado abiertamente esta grave carencia que tiñe -inconscientemente, suponemos- las aportaciones del movimiento de un talante dogmático y partidista. (Gimeno-Bayón, 2015, p. 15)

Por otra parte, tal postura lleva a un distanciamiento práctico y a una especie de ignorancia mutua entre la Psicología de la Religión y la Psicología Transpersonal. Pareciera que cada una de ellas no tuviera noticia de la existencia de la otra, cosa 
que no dice nada bueno de ninguna de las dos.

b) El hecho de extenderse su difusión y su estudio entre sujetos que viven la religiosidad o espiritualidad en forma individualista (es decir, "mi religiosidad o mi espiritualidad es solo mía, la he creado yo a mi medida”) hace difícil las investigaciones cuantitativas que pretendan agrupar a los sujetos en base a sus características comunes. La “dispersión de convicciones y creencias” y los diferentes "platos combinados" de una elección idiosincrásica, dificultan la aplicación de instrumentos convencionales -pensados para un determinado tipo de espiritualidad- y la generalización de conclusiones. La psicometría tiene que ingeniárselas para hacer estudios muy amplios, o reinventar soluciones novedosas cuando es tan difícil su aplicación. Como señala Simkin: “Uno de los problemas que han presentado las técnicas de evaluación de la religiosidad y la espiritualidad en psicología radica en que la mayoría solamente reflejan las orientaciones cristianas y occidentales" (Simkin, 1917b).

c) Que la Psicología Transpersonal haya iniciado su camino sin unos límites definidos (aún menos que los de la Psicología de la Religión y la Espiritualidad, por la liquidez de estos términos, según se ha visto), hace difícil la reducción de su campo de estudio a una estructura común subyacente a los diversos aspectos que de hecho ha tratado. Podría decirse que, a partir de la realidad de su trayectoria, la Psicología Transpersonal se ha ocupa

- de los fenómenos psíquicos que acompañan la vivencia de la espiritualidad (sea lo que sea que esto signifique) y la religiosidad (principalmente la de corte orientalista)

- de los estados modificados de conciencia, parte de los cuales se pueden encuadrar dentro de las experiencias trascendentes o transpersonales

- de otros estados de conciencia, que Rowan (1996) denomina “extrapersonales”, que no hacen referencia a la dimensión trascendente, sino a fenómenos que denotan funcionamientos de la comunicación humana que superan las barreras convencionales de espacio y del tiempo y que entran dentro del ámbito de lo que se llama “parapsicología”: telepatía, sueños premonitorios, mediummismo, espiritismo, etc.. Aquí se pueden citar buena parte de los recogidos por Grof en su lista de estados de conciencia transpersonales y cuya denominación puede llevar a aumentar aún más el embarramiento de un terreno tan pantanoso.

La inclusión dentro de su campo de investigación de los estados de conciencia no habituales se realizó en un ambiente de clara confusión entre: los que reunían las características de lo transpersonal; los que eran estados regresivos; y los que eran intoxicaciones (más propias - estas últimas- del estudio de la psiquiatría o las neurociencias que de la Psicología en sí). Por suerte, Wilber (1992), formuló lo que el denominó "la falacia pre-trans”, dejando claras las similitudes que podían llevar a confundir dos tipos de experiencias bien diferenciadas, así como las contraindicaciones terapéuticas de la provocación de estados pre-personales en sujetos 
con una estructura lábil.

La falta de capacidad, o de preocupación y rigor filosófico para distinguir entre fenómenos místicos, regresivos, paranormales, etc., como se dijo en otro lugar, llevaba a confusiones tales como la de suponer que en esos momentos excepcionales -privados e inefables- de expansión de la conciencia individual permitían acceder a conocimientos objetivos transpersonales. Pero, como señala Ferrer, siguiendo a Habermas, estos fenómenos pueden ser “en el mejor de los casos edificantes, pero siempre epistemológicamente estériles, es decir, incapaces de ajustarse a las demandas objetivas del conocimiento válido de la ciencia empírica” (Ferrer, 2003, p. 53). (GimenoBayón, 2015, p. 43)

Que en el nacimiento de la Psicología Transpersonal estuvieran tan presentes los estudios sobre las “experiencias cumbre” de Maslow, junto con la interesante puerta que se abría, tuvo también su repercusión negativa, pues llevó a la valoración de tal tipo de vivencias en sí mismas, incluyendo la provocación de Estados Modificados de Conciencia a base de ingestión de sustancias variadas (peyote, LSD...). A pesar del posterior desencanto del autor al observar su transitoriedad y su frecuente inutilidad de cara a la autorrealización, y su clara apuesta por lo que llamó "los estados meseta” (Maslow, 1983), más integradores, estables y fructíferos que aquellas experiencias -eso sí, menos vistosos- quedó relegada esta a un segundo plano. Por desgracia, buena parte de los terapeutas que militaban en la Psicología Transpersonal acercaron demasiado cualquier estado alterado de conciencia (incluido el provocado por drogas) y espiritualidad, confusión que sigue permaneciendo en el imaginario de buena parte de las personas que se mueven en el ámbito de la búsqueda psicológico-espiritual. Ello plantea serios problemas respecto a la eticidad de tal enfoque, tanto desde el punto de vista de la salud mental como de la suplantación de la espiritualidad auténtica por sensaciones novedosas. El psiquiatra LeShan, se expresaba con claridad al respecto:

Todas las escuelas serias de meditación, todas las escuelas serias de psicoterapia, han señalado que la búsqueda de la sensación en sí misma, más que favorecer, dificulta o impide el desarrollo interior.[...]

Ciertamente, un estado "alto" puede estar ocasionalmente dotado de un valor real, pues puede mostrarnos el fin que perseguimos en nuestro trabajo y puede también ayudarnos a fortalecer nuestras motivaciones con vistas a superar posibles períodos largos, duros y áridos. Walter Huston Clarck decía: "Las drogas pueden abrir una puerta, pero no nos proporcionan una morada en la que vivir”. Un viaje de LSD realmente aceptable puede elevarnos a las alturas de la montaña desde la que contemplar la tierra prometida por la que luchamos. Pero una elección se hace entonces necesaria: podemos permanecer en la montaña con ayuda de más LSD, o descender a la base y afrontar la larga y difícil tarea de atravesar el desierto para llegar hasta allí. Que cada cual elija por sí mismo. (LeShan, 1986, p. 135s.) 
d) El traspaso de la "abstención de la trascendencia” y de la "neutralidad benevolente" ha llevado a que, en demasiadas ocasiones, la Psicología Transpersonal, en su exposición teórica y en su aplicación práctica, haya dado lugar a un tipo de dogmatismo camuflado, que da por sentada la realidad objetiva de afirmaciones que no son otra cosa que una opción filosófica o religiosa. La aceptación, sin más, del llamado "perennialismo" de Huxley (1977) como algo incuestionable destroza todas las barreras de rigor intelectual que la ciencia debe respetar. Ferrer expresa su disgusto respecto a tal postura, cuando señala que el perennialismo:

1) es una postura filosófica apriorística, 2) favorece una metafísica monista no dual, 3) está orientado hacia una epistemología objetivista, 4) se inclina hacia el esencialismo y, por consiguiente, 5) tiende a caer en el dogmatismo religioso y en la intolerancia a pesar de su alegada postura inclusivista. (Ferrer, 2003, p. 124)

A ello se suma que el autor más leído e influyente en la Psicología Transpersonal, Ken Wilber (aunque este decidió abandonar su encuadre para pasarse al campo filosófico) adoptó una posición claramente partidaria de jerarquizar la valía objetiva de las diferentes religiones al plantear su modelo filosófico-psicológico (Wilber, 1991). El resultado es que el modelo posee un sesgo orientalista claro, por ejemplo, al considerar como estados espirituales superiores aquellos pertenecientes a tradiciones orientales no-dualistas, en concreto a la escuela hindú Advaita vedanta y al budismo mahayana y tibetano (Dzogchen, en particular). De ese modo el modelo relega a la mayor parte del misticismo judío, cristiano y musulmán a un nivel de logro espiritual inferior, por no hablar de las formas indígenas y chamánicas de espiritualidad (Noguera Ferrer, 1999, p. 88).

Por supuesto que hay honrosas excepciones y autores que mantienen el sabio principio de Flournoy, pero es bastante común, entre los autores de Psicología Transpersonal, vender conjuntamente psicología y religión, en un solo lote y sin previo aviso, saltando todas las precauciones que una epistemología científica debiera conocer y ejercitar.

Por otra parte, el hecho de que los destinatarios iniciales (y buena parte de los actuales) no tuvieran -en general- una cosmovisión religiosa o filosófica que permitiera unificar los valores y preguntas últimas de la persona, ha llevado a sesgar la ubicación de la Psicología y a una "psicologización de la experiencia religiosa" y a buscar en la Psicología las respuestas propias de la religión (institucional o no, teísta, atea o agnóstica).

\section{Retos a Superar}

Con todo lo ya expuesto, queda patente que la Psicología Transpersonal, y en consecuencia su aplicación a través de la dimensión psicoterapéutica, tiene unos cuantos retos a superar:

a) El reto de dialogar con la cultura de su campo de estudio precedente y con la Psicología de la Religión, para enriquecerse de ese diálogo y enriquecer también 
a esta disciplina.

b) El reto de no reprimir en sus estudios los fenómenos psíquicos que se dan en el seno de religiones institucionalizadas, en especial los monoteísmos más presentes en las culturas occidentales. El reto de incluye no dejar fuera de la investigación los fenómenos psíquicos (motivaciones, repercusiones en sus cogniciones, estilos de personalidad, patologías, etc.) de quienes viven una religiosidad extrínseca, para utilizar la terminología de Allport (1950).

c) El reto de distinguir con claridad -dentro de sus estudios sobre estados de conciencia no habituales- lo que son experiencias transpersonales, prepersonales y extrapersonales, creando también ámbitos de estudio adecuadamente diferenciados para cada una de ellas y de herramientas terapéuticas específicas para las patologías que se puedan presentar en sus respectivos marcos. Especialmente delicado resulta aquí la aplicación indiscriminada de técnicas catárticas o la ingestión de sustancias, sin tener en cuenta el contexto clínico de cada sujeto, la estabilidad de su organización intrapsíquica, sus motivaciones no conscientes, etc., a fin de evitar que esas intervenciones puedan llevar a provocar un desequilibrio o una fractura interna, más que a una sanación y un crecimiento personal y transpersonal.

d) El reto de ejercer sus tareas científicas y psicoterapéuticas con una eticidad respetuosa del marco de devoción y de referencia religiosa de cada uno de los sujetos que acuden a pedir psicoterapia, desde una actitud de “abstención de trascendencia” y sin pretender-a veces inconscientemente-que participen de uno específico (el del terapeuta). Los beneficios que puede aportar la inclusión de la dimensión espiritual como parte de las vivencias internas más importantes del sujeto (pues así es muchas veces), no consistirá, como señala González Valdés, en hacer proselitismo, sino en “aprovechar la tendencia natural y espontánea de los propios creyentes en aras a su salud” (González Valdés, 2004, p. 26), lo que incluye, según esta autora, distanciarse de la minimización de las creencias, o pretender eliminarlas o cambiarlas "puesto que solo conseguiría con ello destruir el rapport y la empatía que todo trabajador de la salud debe tener” (González Valdés, 2004, p. 26).

e) Otro reto a superar, compartido con la Psicología de la Religión, es el de afinar a la hora de precisar y evaluar los constructos con los que trabajan, porque, además de lo que se indicó respecto a la ambigüedad de los constructos “religión” y "espiritualidad”, hay constructos que se solapan, "mientras que algunos autores definen los constructos numinosos como orientaciones motivacionales (Allport y Ross, 1967) otros los comprenden como rasgos de la personalidad (Piedmont, 2004) o estrategias de afrontamiento (Pargament et al., 2000)” (Simkin, 2017a, p. 180).

Ahora bien: por muchos y relevantes que sean esos retos, el principal desafío que existe hoy en este ámbito lo tiene planteado la Psicología, como disciplina científica (y su aplicación a la psicoterapia), y consiste en dar la atención que merece al tema, ya que es imposible comprender a la mayoría de sujetos, para los cuales "la religión es un tipo de ideología muy particular, que involucra al individuo en un compromiso único, en la ausencia de evidencia o argumento racional, y en una 
red única de relaciones, reales e imaginadas” (Beit-Hallahmi y Argyle, 1997, p. 5). Eso sí, aquí se trata de interpretar el término en sentido amplio como generador de significado existencial y de procesos de afrontamiento de las dificultades vitales.

Cohen se extraña de la poca atención que ha merecido el estudio de la religiosidad dentro de la Psicología, apuntando que "es uno de los mayores agujeros en la psicología, una parte críticamente importante de la vida humana, pero que no recibe la atención empírica que merece” (Cohen, 2015) y señala cuatro razones por las que la religión es importante para ser estudiada por los psicólogos:

1. La religión es una base central para el juicio moral.

2. La religión moldea ampliamente la autoconceptuación.

3. La religión afecta fuertemente las relaciones interpersonales e intergrupales.

4. La religión brinda una interesante oportunidad para considerar la forma en que las fuerzas culturales moldean la psicología de las personas en formas complejas (Cohen, 2015, p. 77).

Si no se quiere limitar artificialmente el estudio del psiquismo humano, toca tomar nota de que la religiosidad influye configurando lo más íntimo del mismo, empezando por el funcionamiento y estructura cerebral. Ya hace unos cuantos años que Zohar, la creadora del constructo "inteligencia espiritual” daba cuenta de los hallazgos de las investigaciones en la Universidad de California del neurólogo Ramachandran y su equipo (Zohar, 1997). Estos llegaron a la conclusión de la existencia en el cerebro humano de lo que llamaron "el punto divino", situado entre las conexiones neurales de los lóbulos temporales. Esta zona se activaba exclusivamente-como pudieron comprobar por los escáneres- cuando los sujetos hablaban de temas espirituales y religiosos. Actualmente, desde la neurociencia se están realizando interesantes investigaciones en torno al tema. Algunas de ellas son tan específicas como la que recoge Tobeña en su investigación (Tobeña, 2012), en la que ha encontrado diferencias entre "el cerebro ateo" y el "cerebro religioso":

Las medidas de religiosidad permitieron derivar grandes vectores que presentaron covariaciones con volumenes zonales de la corteza cerebral: así, la "experiencia de una relación íntima con Dios", covariaba positivamente con los volúmenes de las zonas anteriores y medias de los lóbulos temporales; el "miedo a la ira divina" covarió negativamente con el volumen de regiones orbitofrontales y parietales; y el "pragmatismo y la incredulidad religiosa" con regiones parietales (el precuneus derecho, particularmente) (Tobeña, 2012, p. 49).

La Psicología -a la hora de impartir formación a los profesionales-no se puede permitir dejar de lado las dinámicas internas provocadas por la dimensión espiritual del ser humano, ni estados de conciencia que parecen difíciles de comprender. No es lícito utilizar un mecanismo de negación para evitar entrar en temas espinosos. Algunos, sobre todo dentro del área sanitaria de los cuidados a enfermos terminales, se sienten francamente desconcertados al observar la inexistencia de formación en el tema por parte de las instituciones que se ocupan de los profesionales de la salud. 
Especialmente ocurre eso con los que se enfrentan día a día con situaciones extremas, necesitados de tener parámetros profesionales y científicos para abordar los requerimientos espirituales del paciente sin tener herramientas para ello, dejándolas exclusivamente a la intuición personal del profesional. Por ello:

se hace evidente la necesidad de que quienes se encuentren en proceso de formación avanzado como también las sociedades y entidades de formación académica, realicen aportes y agilicen los procesos requeridos para estandarizar el rol o competencias del psicólogo para el abordaje de la dimensión espiritual en el contexto de la salud. Por tanto, se dé lugar al desarrollo de cátedras, cursos de profundización, diplomados u otros con el fin de promover y desarrollar el trabajo de la dimensión espiritual en la práctica profesional. (Orozco et al., 2019, p. 46)

Quienes, más allá del campo académico, trabajan en el campo clínico, conocen la relevancia del tema. Son muchas las voces que reclaman esta atención:

"Incluir el aspecto espiritual o de inteligencia espiritual en nuestro quehacer investigativo y clínico es imprescindible para que nuestras explicaciones e intervenciones clínicas sean cónsonas con la realidad de las poblaciones en las que intervenimos” (Scharrón del Río, 2010, p. 87).

De esta manera, se puede lograr un entendimiento más completo de las dinámicas interpersonales y de relaciones objetales de las personas en terapia, lo cual potencialmente puede ayudar a informar los objetivos terapéuticos y a promover cambios (Scharrón del Río, 2010, pp. 87 y 102).

Esta autora, con Tucker (2002), observa cómo, entre la población menos privilegiada, la atención psicológica profesional queda más lejos (en términos de conocimiento, economía y confianza) que la que ofrecen las diferentes instituciones religiosas que les están prestando servicios de otro tipo, y a las que acuden para momentos de tránsito vital (nacimiento, matrimonio, muerte).

Tanto las minorías étnicas en los Estados Unidos y las poblaciones de escasos recursos en Puerto Rico, Latinoamérica y los Estados Unidos encuentran en los sistemas religiosos instancias de conexión, de unión, de apoyo. También encuentran sentido de pertenencia, identidad, optimismo y esperanza (Scharrón del Río, 2010, p. 101).

De otra parte, la comprensión del paciente que acude a psicoterapia se enriquece cuando se observa cómo diferentes religiones específicas favorecen o no algunos procesos psicológicos. Así lo constatan Cohen et al. (2006), en cuanto a la diferencia de predisposición al perdón entre el cristianismo y el judaísmo, o Tsai et al. (2007) en cuanto a la diferencia de valoración y promoción de las diferentes emociones, entre cristianos y budistas, ya que en sus investigaciones concluyeron que mientras los primeros priorizan como estado afectivo ideal los estados positivos de alta excitación, los segundos lo hacen con los estados positivos de baja excitación.

No se puede dejar de constatar que una gran parte de las investigaciones que se han realizado en los últimos años en este campo proceden de los profesionales 
de la medicina paliativa, que se encuentran cómo, ante la antesala de la muerte, la religión y la espiritualidad juegan un papel primordial, básicamente como factor protector: "se han realizado una serie de investigaciones que aportan evidencia que la coloca como una necesidad de atención de los pacientes, ya que entre otras cosas, impacta sobre variables como las conductas de cuidado de la salud y la calidad de vida (Sandoval Guzmán et al., 2014, p. 334). Son ya centenares las investigaciones empíricas que se han llevado a cabo en este terreno, a diferencia de lo que había ocurrido en décadas anteriores (véase en Garcés, 1985). Probablemente la más abarcativa de estas investigaciones es el metaanálisis realizado por Koenig et al. (2001) en el que:

ofrecieron un análisis crítico, sistemático y amplio de más de 1200 estudios empíricos y 400 revisiones que examinaron las relaciones entre espiritualidad y religión y variadas condiciones físicas y psíquicas. Estudios correlacionales y longitudinales que incluyeron enfermedades cardíacas, hipertensión, enfermedad cerebro-vascular, disfunción inmunológica, cáncer, mortalidad, dolor y discapacidad, mostraron entre un $60 \%$ y un $80 \%$ de relación entre mejor salud y religión o espiritualidad. Las condiciones psiquiátricas revisadas incluyeron psicosis, depresión, ansiedad, suicidio y problemas de personalidad. Los beneficios de la espiritualidad según estos autores son triples: ayudan a la prevención, aceleran la recuperación y promueven la tolerancia frente al padecimiento. (Salgado, 2014, p. 134)

\section{Y a Pesar de lo que se Echa en Falta...}

Aún con todas las carencias indicadas y desafíos a superar, la Psicología Transpersonal tiene la virtud de llenar un hueco para la comprensión del ser humano y el abordaje de fenómenos y problemas psicológicos que de otra forma quedarían almacenados en el mundo de la represión científica.

Ciertamente, se puede argumentar que del estudio del psiquismo de la espiritualidad y la religiosidad ya se encarga la Psicología de la Religión, ya que comparte con ella el estudio científico de la dimensión del ser humano en la que se pregunta por los significados últimos de su experiencia y su existencia (espiritualidad, o religiosidad en sentido amplio). Pero ya se ha visto que entre ambas disciplinas, a la hora de abordar el tema, hay algunas diferencias que no por ser sutiles son irrelevantes: los estudios que se realizan por parte de los psicólogos de la Religión se realizan en colectivos poco afines a los que estudia la Psicología Transpersonal, colectivos con una experiencia espiritual poco institucionalizada y de una religiosidad variopinta, no exenta a veces de contradicciones. No por ello, siendo una dimensión tan nuclear en el ámbito de la motivación, la afectividad y el comportamiento, se puede abandonar a este colectivo, cada vez más numeroso, a la incuria investigadora. Como señalaron King y Dein: "Desafortunadamente, una concentración en la variable religiosa ha llevado a no apreciar el concepto más amplio de espiritual y la presunción de que si alguien no profesa una fe religiosa 
reconocida, no tiene discernimiento o necesidad espiritual” (King y Dein, 1998, p. 1259). La mayor flexibilidad de la Psicología Transpersonal le dota de unas posibilidades de acceder a ámbitos sociales que, hoy por hoy, resultan más difíciles para la Psicología de la Religión.

Pero además, por su vocación terapéutica, es imprescindible para la clínica, a la hora de realizar diagnósticos discriminatorios entre una espiritualidad o religiosidad sana y una vivencia patológica de las mismas, tanto si se realiza desde una visión atea, agnóstica o de otras cosmovisiones. Y consecuentemente a ello, ofrecer los recursos terapéuticos que lleven a la reordenación de las vivencias disfuncionales en este terreno hacia la salud mental y hacia el crecimiento personal.

Se podría pensar también que si se entiende la religiosidad en esa forma tan amplia que expresaba Frankl -cuando las equipara a la pregunta por el sentido de la existencia-, este área ya estaría cubierta por la Psicología y psicoterapia Existencial. Pero la religiosidad no solo incluye a las personas que se hacen preguntas, sino a aquellas que están convencidas de haber encontrado o intuido parte de las respuestas en un marco de referencia, sea colectivo (religión) o individual (espiritualidad), área a la que la Psicología y psicoterapia Existencial permanecen ajenas.

Hay también un espacio psicológico y psicoterapéutico que la Psicología Transpersonal ha afrontado con claridad y sobre el que ha realizado muchos estudios e intervenciones: estados de conciencia no habituales. Quedan todavía muchas preguntas por responder en relación con lo que se llaman fenómenos parapsicológicos a los que solo parece haber prestado atención la Psicología Transpersonal: ¿qué configuración psicológica explica los fenómenos conocidos como "sueños premonitorios" de desgracias (tsunamis, incendios, muertes) que narran algunas personas, mayoritaria, pero no únicamente, pertenecientes a determinadas culturas centroamericanas?, ¿hay algunos rasgos de personalidad diferentes en las personas que relatan experiencias de telepatía o escritura automática?, ¿qué explica, desde el punto de vista psicológico, las vivencias de fenómenos extraños, o sensación de presencia de personas recientemente muertas de la que dan cuenta bastantes personas, como señala Pastor (2019) a propósito de sus investigaciones científicas?

A la hora de realizar investigaciones convencionales, la Psicología de la Religión ha dedicado un gran esfuerzo a la confección de escalas que recogen diferentes aspectos de la religiosidad y espiritualidad. Quiceno y Vinaccia, por ejemplo, dan cuenta de veinte escalas psicométricas hasta el año 2005 (Quiceno y Vinaccia, 2009), si bien es cierto que tales escalas se quedan cortas a la hora de matizar esos constructos, pues, como señalan King y Dein (1998), quedan limitadas, frecuentemente, a la observación de la variable del cumplimiento extrínseco de comportamientos religiosos. La Psicología Transpersonal ha centrado más sus investigaciones empíricas en conocer aspectos relacionados con los efectos de la meditación de corte oriental así como la capacidad de modificar el propio estado de conciencia a través de la misma, o de producir esas modificaciones voluntarias o semivoluntarias mediante la utilización de sustancias o la respiración holotrópica, 
y sus repercusiones positivas en la salud mental. Ambas disciplinas pueden aunar y complementar esfuerzos para beneficio de la comprensión del ser humano.

\section{Una Propuesta Específica de Psicoterapia Transpersonal}

\section{El Panorama General de las Psicoterapias Transpersonales}

Como se ha dicho, fruto de su vocación psicoterapéutica, la Psicología Transpersonal ha dado ya numerosos frutos en términos de ofrecer instrumentos diagnósticos y de intervención ante problemas que derivan de una mala gestión de la dimensión trascendente del ser humano. Pero, salvo el modelo global de la Psicosíntesis de Assagioli, pareciera que las otras aportaciones ofrecen un panorama:

a) fragmentado, al abordar aspectos concretos del psiquismo, desconectándolos del resto, y aportando soluciones respecto a esa área concreta, como si no estuviera intensamente relacionado con la complejidad unitaria del sujeto.

b) a veces, en su práctica por parte de profesionales no suficientemente entrenados, pueden observarse intervenciones imprudentes, por no tener en cuenta la fragilidad o fortaleza de la estructura del sujeto al que se le aplican técnicas catárticas, que le pueden llevar a regresiones pre-personales para las que no está preparado; o al que se le sugiere la ingestión de sustancias que le pueden llevar a disociaciones que se estabilizan en el tiempo.

c) demasiado frecuentemente implican la aceptación de un marco religioso concreto, que puede no ser el del paciente, distorsionando este para ajustarlo a la intervención o principios del propio terapeuta o modelo. Las psicoterapias transpersonales se han difundido mayoritariamente entre individuos sin una cosmovisión institucionalizada, muchas veces sincrética. Frecuentemente se muestran en un contexto cultural occidental pero insertando la intervención en un contexto de constructos culturales de otras culturas, sobre todo orientales (con su peculiar énfasis en el término "energía”) o indigenistas (como el chamanismo, con su asunción del politeísmo), que pueden crear disociaciones internas en el paciente, muchas veces no conscientes, en lugar de unificarle en forma integradora.

No quiere eso decir que el terapeuta tenga que rechazar referirse a los contenidos de la cosmovisión a la que se adscribe el paciente, sino que la obligación de abstenerse del diagnosticar el valor objetivo de las creencias, conlleva estar atento exclusivamente a la dinámica psicológica de las mismas, salvo que el cliente solicite entrar en los contenidos y el terapeuta esté preparado específicamente para ello. Este sería el caso de quien acude a un terapeuta con el que comparte cosmovisión y que tiene competencia por sus conocimientos avanzados en ella para abordar el tema.

El enfoque transpersonal llevará al psicoterapeuta, por ejemplo, a darse cuenta de que algunas angustias y dificultades que le plantea el sujeto que acude a terapia es porque está viviendo un “despertar espiritual” (en términos de Assagioli, 1993a; 1993b), o una "emergencia espiritual” (Grof y Grof, 1993a; 1993b; 1993c; Lukoff et al., 1998) y tratar estas dificultades en forma precisa, sin pretender asimilarlas a 
las patologías tradicionales. Justamente por la especificidad del problema no está de más la categoría introducida en el DSM-IV (American Psychiatric Assocciaton, 1994 )-a instancias de las psicoterapeutas transpersonales- del "problema religioso o espiritual”, entre los que podían ser objeto de atención psicológica.

La abstención de trascendencia resultará más fácil en aquellos modelos terapéuticos que ponen énfasis en lo que Rychlak (1988) denomina "causa formal” de la psicoterapia (como por ejemplo, la Psicoterapia de la Gestalt, o el modelo de Psicoterapia Integradora Humanista, que luego se expondrá sucintamente). En ellos la atención no se centra tanto en contenido psíquico como a la dinámica del proceso mismo.

d) algunos psicoterapeutas descuidan las tareas propias de su profesión dentro del espectro convencional para sesgarlo hacia la dirección de maestro espiritual. Gregoire (1986) a propósito de la meditación, avisa de esta tentación y de la de conducir al paciente más allá del contrato terapéutico. De este modo puede ocurrir que, en lugar de derivarlo hacia la autonomía, lo deriva hacia el reforzamiento de las defensas. Ello, unido a la falta de espacio de formación académica y científica, como antes se dijo, puede llevar a confundir en los propios profesionales sus deseos narcisistas (hacer de gurú), o sus anhelos espirituales con las necesidades de la persona que tienen en la sala de terapia. Si a esto se le añade el caos informativo de las redes sociales, el cambio de paradigma cultural, científico y teológico (vid. Capra et al., 1994), podemos llegar a una situación como la que - en forma caricaturesca, pero no inverosímil- describen Cornejo Valle y Blázquez Rodríguez:

Una de las manifestaciones más desconcertantes pero interesantes de la espiritualidad contemporánea podría describirse así: hoy en día uno puede encontrar en internet, en cualquier idioma, una dieta ayurvédica recomendada por un chamán converso al budismo que tiene un blog de feng shui y se gana la vida como formador de mindfulness, aparte de alguna sanación chamánica cuando surge. Menos complicado que lo anterior, no obstante, quizá el lector ya conoce alguna enfermera o enfermero que ofrecen reiki a sus pacientes, o algún doctor o doctora que recomiendan meditación, o algún devoto o devota cristianos que han sustituido la oración por el yoga. ¿Qué está ocurriendo en las culturas religiosas y de la salud para que semejante eclecticismo haya llegado a ser posible? Aunque Jürgen Habermas usara la expresión "sociedad postsecular" para referirse casi únicamente a las nuevas formas de convivencia entre iglesias y estados, la expresión permite imaginar toda una nueva fenomenología histórica de la religión de la que aún debemos dar cuenta. (Cornejo Valle y Blázquez Rodríguez, 2013, p. 12)

\section{Una Propuesta Concreta}

En la década de los ochenta del siglo pasado, la autora de este escrito, junto con Ramón Rosal, crearon el modelo de psicoterapia denominado Psicoterapia 
Integradora Humanista. En los años 2001 y 2003 se publicó la primera edición de los dos volúmenes que lo resumen (Gimeno-Bayón y Rosal, 2016; 2017).

En 2006 la autora publicó -en el seno del Instituto Erich Fromm de Psicoterapia Humanista- un volumen de Psicología Transpersonal que sintetizaba y bosquejaba ya la línea seguir, dentro de las diferentes posibilidades de esta disciplina (Gimeno-Bayón, 2015). Dado que los creadores del modelo entienden al ser humano como unidad biopsicosocioespiritual, dicha línea optaba por la continuidad entre psicoterapia-autorrealización, incluyendo en esta última el desarrollo de valores éticos y espirituales. En tal sentido, y sin tomarlo de una manera rígida, abogaba por el planteamiento de la Psicosíntesis (Assagioli, 1973) de enfocar la psicoterapia hacia lo que este modelo llama "psicosíntesis personal" y, en una segunda fase -y si así lo reclama y desea el usuario de la psicoterapia- hacia la "psicosíntesis transpersonal”. Es decir: si la persona que acude a terapia presenta graves disfunciones en el terreno de la psicopatología convencional, abordar estas prioritariamente, aunque la demanda sea de tipo transpersonal, puesto que las primeras influirán en una distorsión de las segundas. Naturalmente, este planteamiento en abstracto tiene múltiples modalidades en la práctica, teniendo en cuenta que cada persona exige un proceso individualizado. Mucho más cuando manifiesta interés en seguir creciendo en el ámbito transpersonal (bien porque traiga consigo esta preocupación o porque vaya naciendo la apertura a la motivación espiritual conforme se va desarrollando exitosamente la psicoterapia). Puede ocurrir también que en una persona sensible a los valores espirituales y, consciente de que ha anclado su sentido de la vida en ellos, no se puedan desentender los problemas puramente psicológicos de la referencia a este otro ámbito, que actúa con instancia supraordenada y que, en definitiva, dota de orientación y significación a todo el conjunto de su existencia, psicoterapia incluida. Ello significa que algunas personas de las que acuden a psicoterapia aquejadas por problemas psicológicos de los que figuran en los manuales de diagnósticos habituales, en algunas ocasiones, no pueden recibir un tratamiento limitado a estos sin imbricarlos en un panorama más amplio que requiere otro mapa más abarcativo que incluya el del "mundo de lo invisible” (por llamarlo de alguna forma). Ese mundo que acoge experiencias de sentido que se rigen por normas no necesariamente iguales a las del universo empírico. En estos casos se trata, no tanto de negar la validez de la psicoterapia convencional, como de incluirla dentro de un paradigma más amplio en el que esta queda subsumida y re-significada a la luz de unos valores que traspasan el ámbito del pragmatismo psicológico.

Dentro del modelo de Psicoterapia transpersonal Integradora Humanista, claramente se distinguen dos direcciones: la dirección horizontal, enfocada hacia los valores éticos (dentro de la línea desarrollada por Rosal, 2003 y 2012; Rosal y Gimeno-Bayón, 2010); y la dimensión vertical, enfocada hacia una dimensión trascendente, que traspasa aquellos -a la vez que los integra- en base a la intuición de otros valores, a veces paradójicos o contradictorios respecto a los valores pragmáticos convencionales. No otorga especial atención, si la situación no lo 
requiere, a los estados modificados de conciencia (EMC), pues aspira a que el desarrollo transpersonal conduzca, más bien, a lo que da en llamar EMV: Estados Modificados de Vida cotidiana.

\section{La Psicoterapia Transpersonal Integradora Humanista}

Eso sí, la Psicoterapia Integradora Humanista, en su vertiente transpersonal, conserva el esquema básico propio del modelo, y contempla las mismas fases del ciclo del fluir vital y las dificultades que a ese fluir pueden aportar los bloqueos, dispersiones o distorsiones del mismo, así como posibles pautas de intervención, ahora en la dimensión espiritual. En el presente artículo no se hará referencia a ellas, pues difícilmente se podrían sintetizar (véase en Gimeno-Bayón, 2019a). Pero sí puede esbozar las actitudes hacia las que enfoca el crecimiento transpersonal (Gimeno-Bayón, 2015) en sus dimensiones horizontal y vertical, teniendo en cuenta que, si la primera no está suficientemente afianzada (aunque siempre es susceptible de seguir creciendo) la segunda puede adquirir fácilmente un carácter defensivo. Así pues, y a modo de esquemática enumeración, a partir del ciclo del fluir vital que contempla la Psicoterapia Integradora Humanista, se ofrece el siguiente esquema de integración espiritual para el ciclo sano:

En su Dimensión Horizontal, la motivación espiritual subyacente es la tendencia a la búsqueda de comunión con todos los seres de la realidad empírica, el vínculo con todo lo que existe. Recorriendo las diferentes fases, se puede observar que algunas de las actitudes a desarrollar vienen reconocidas como valores éticos en buena parte de las grandes tradiciones filosóficas y religiosas. Se pueden enumerar así:

1. Fase de receptividad sensorial. La actitud propia de esta es la cordialidad, entendida como vinculación amorosa, acogida bondadosa hacia todo.

2. Fase de filtración de sensaciones. La apertura a la experiencia del otro, sin ombliguismo ni explotación, es la característica de esta fase.

3. Fase de identificación afectiva, caracterizada por el amor como puro existir para el otro (ágape), compasión, simpatía, indignación, compartir para ser ayudado. Incluye la amistad, el amor desinteresado y el alegrarse con los otros.

4. Fase de identificación cognitiva, en la que la empatía juega un papel primordial.

5. Fase valorativa, regida por el principio de solidaridad entendida como justicia social, cooperación y cuidado de los otros.

6. Fase de decisión que incluye la entrega comprometida, sentido de responsabilidad hacia el otro y aceptar también la entrega de este.

7. Fase de movilización caracterizada por una esperanza, apasionada y confiada.

8. Fase de planificación que requerirá el ejercicio de una constante creatividad.

9. Fase de ejecución de la acción de compartir, que activa tanto la misericordia como la petición confiada y la cooperación sinérgica.

10. Fase de encuentro donde tiene lugar la experiencia de comunión, como 
respuesta afirmativa ante la Vida, que reúne todo y a todos en su seno.

11. Fase de consumación que dará lugar a la ampliación del yo. Ahora al sujeto, como consecuencia de la transformación que opera el encuentro, le importan cosas que antes no importaban. Hay una extensión del sentimiento de sí mismo.

12. Fase de relajamiento en la que surgen espontáneamente el agradecimiento como recuerdo de lo valioso recibido, la confianza en el futuro y la capacidad perdón.

13. relajación paz interior, caracterizado por una experiencia de serenidad y plenitud, similar a la que describe Maslow como "experiencia de meseta”, esa “dicha serena y cognoscitiva” (Maslow, 1983, p. 415).

En su Dimensión Vertical, la motivación subyacente es la tendencia a la unión con la Trascendencia (por poner un nombre a lo que en diferentes cosmovisiones se llama Divinidad, lo Sagrado, el Misterio Último, la Realidad Fundante, lo Totalmente Otro, lo Uno, etc.). Las actitudes a vivir en el desarrollo de las distintas fases de un ciclo sano, son las siguientes:

1. Fase de receptividad sensorial. El inicio del ciclo vertical se desarrolla a partir de una actitud contemplativa, como disposición a ir más allá de la visión utilitarista, desde la admiración y el "asombro filosófico" (Lersch, 1971).

2. Fase de filtración de sensaciones, caracterizada por el recogimiento, el silencio, el aquietamiento de la agitación, relativización y acostumbramiento a ver la trascendencia en la vida cotidiana.

3. Fase de identificación afectiva, en la que se da el "entusiasmo" en el sentido original de estupefacción, alegría ante la grandeza de una Realidad inefable, y veneración y adoración de su sacralidad.

4. Fase de identificación cognitiva, cuya actitud viene marcada por el realismo (humildad de "humus") frente a esa realidad supranatural, y el reconocimiento de la contingencia y relativización de nuestro yo y nuestros conocimientos.

5. Fase valorativa, en la que se da una subversión de valores convencionales a la luz de los valores novedosos de esta dimensión invisible de la realidad.

6. Fase de decisión, en la que tiene lugar una adhesión al Misterio (sea una adhesión personal gradual o súbita), al proyecto que lo Absoluto parece sugerir al sujeto y que incluye aceptación de cambios no proyectados.

7. Fase de movilización. Esta fase se caracteriza por la búsqueda del desarrollo de tal proyecto ayudándose de medios como la meditación, la oración, el rito y otros recursos similares (véase en Gimeno-Bayón, 2019b).

8. Fase de planificación, que -curiosa y paradójicamente-incluye a la vez la planificación coherente con el objetivo y el desapego de la propia planificación y de los medios de la misma, incluyendo los económicos y las posesiones sociales $\mathrm{y}$ afectivas.

9. Fase de ejecución de la acción. La actuación correspondiente a ella se podría denominar como de “absorción en la danza”, es decir de una actuación armoniosa e íntegra en lo cúltico, en lo interno, en la transformación social y en las acciones cotidianas. 
10. Fase de encuentro, en la que se produce lo que se ha dado en llamar comunión mística, y en la que lo supranatural engulle en su ámbito al sujeto (como experiencia cumbre o de meseta), y se produce un ansia de fusión total.

11. Fase de consumación, en la que se opera algún tipo de transformación en la persona, como consecuencia de salir del encuentro impregnada de lo Absoluto.

12. Fase de relajamiento. Fruto del proceso anterior, se produce un descentramiento (el centro del sujeto está en otro lugar diferente, más íntimo y hondo que antes del encuentro) y re-centramiento en ese otro nuevo lugar hacia el que se desliza el sentimiento de la propia identidad.

13. Fase de relajación. Lo típico de esta fase es el abandono al Misterio, en el que se da un desprendimiento confiado, no solo de lo que se tiene sino también de lo que "se es", a la vez que hay una extinción del miedo y la angustia por ese desprendimiento, y en su lugar hay una paz confiada de "estar en buenas manos".

\section{Psicopatología Transpersonal}

Al igual que hace el modelo en el ciclo del fluir vital personal, se ha procedido a identificar una serie de problemas que impiden el desarrollo sano transpersonal, clasificados - lo mismo que aquellos-a partir de los bloqueos, dispersiones y distorsiones que se pueden dar en cada fase. Hay algunos autores y modelos que detectan patologías referentes a un marco religioso concreto -e.g. Garrigou-Lagrange (1957) o McNamara (1979) respecto al cristianismo, Wilber (1994c) respecto al hinduismo advaita- y dan indicaciones y pautas para superarlos. En el ciclo transpersonal de la Psicoterapia Integradora Humanista, dentro de las patologías observadas -fruto de la práctica clínica- se recogen también las de estos y otros autores, integrándolas dentro del lugar correspondiente del ciclo. En conjunto (Gimeno-Bayón, 2019), se han descrito y sugerido propuestas terapéuticas respecto a 84 problemas. Por ejemplo: en la fase de identificación afectiva se han identificado como:

a) Bloqueos

- Bloqueo de la afectividad espiritual

- Depresión reactiva

- Desánimo institucional

b) Dispersiones

- Gula espiritual

- Estados regresivos

c) Distorsiones

- Masoquismo

- Emocionismo solidario

- Fatiga por compasión

- Pseudo-realización

Mientras en la fase de identificación cognitiva se han identificado como:

a) Bloqueos

- Autoimagen narcisista 
- Fideísmo

b) Dispersiones

- Religión a la carta

- Falta de integración de los distintos tipos de cognición

c) Distorsiones

- Reduccionismo cientifista

- Reduccionismo espiritualista

- Fracaso en la integración-identificación

- Enfermedad de Arhat

\section{Conclusiones}

La Psicología Transpersonal y su correlato en psicoterapia enfrentan un campo de estudio (o mejor dicho, más de uno) que la Psicología convencional elude convertir en objeto de formación académica para los profesionales de la psicoterapia. Uno de ellos, es la espiritualidad.

No cabe duda de que durante décadas, se ha evitado investigar la espiritualidad por considerársele nada científico. Al respecto Rivera (2007) señala que el área espiritual de la vida humana ha sido largamente segregada del campo de la psicología, y parece ser necesario, hoy por hoy, asignarle un lugar más allá del apasionamiento de la fe y el escepticismo academicista contemporáneo. (Salgado-Levano, 2016, p.2)

¿En cuántas de nuestras universidades se estudia, dentro de la formación en psicología clínica (a diferencia de lo que ocurre en otros países), el tema de la espiritualidad o la religiosidad? ¿Qué se espera de los psicólogos sanitarios y clínicos cuando tengan que enfrentarse en la sala de terapia a la incidencia de estas dimensiones en el proceso psicoterapéutico? ¿Podrán discriminar entre una vivencia sana de una vivencia patológica de las mismas? ¿ Tendrán que dirigirse los pacientes -disociando el proceso- a dirigentes religiosos, buena parte de ellos sin conocimientos de las dinámicas del psiquismo, o a osados pseudogurús que practican el intrusismo profesional pero que ofrecen acoger esas inquietudes? ¿Mejor asumir, invadiendo un campo que no es el propio, el rol de guías espirituales? De momento, parece que a la mayoría de los psicólogos se les podría aplicar afirmaciones como las siguientes, referidas al ámbito médico:

Asimismo, los estudios reportan que el personal de salud identifica barreras para la atención espiritual de los pacientes, entre ellas se cuentan: la formación exclusivamente biomédica del clínico, en la que se consideran a los aspectos espirituales como poco relevantes; un entrenamiento inadecuado para la identificación de estas necesidades, dudas sobre su incorporación a la intervención, la ausencia de una postura u orientación espiritual en la vida de algunos profesionales; así como la ignorancia de los efectos positivos de la espiritualidad sobre la salud. (Sandoval Guzmán et al., 2014, p 334) Se hace evidente la necesidad de que quienes se encuentren en proceso 
de formación avanzado como también las sociedades y entidades de formación académica, realicen aportes y agilicen los procesos requeridos para estandarizar el rol o competencias del psicólogo para el abordaje de la dimensión espiritual en el contexto de la salud. Por tanto, se dé lugar al desarrollo de cátedras, cursos de profundización, diplomados u otros con el fin de promover y desarrollar el trabajo de la dimensión espiritual en la práctica profesional. (Orozco et al., 2019, p. 46)

Son ya muchos autores los que dentro del ámbito de la salud mental y física reclaman esa formación (vid., además de los citados, Vieten et al., 2013).

Por otra parte, a salvo de lo investigado por la Psicología Transpersonal, sigue pendiente la respuesta institucional y académica sobre qué disciplinas se harán cargo del estudio científico de los fenómenos psicológicos asociados a estados modificados de conciencia, cuando estos se producen en forma espontánea, pues como señala Rubia (2003), si bien se conocen -al menos desde la neurobiología- el funcionamiento de experiencias como las del éxtasis (o similares a las descripciones de este por parte de los místicos) cuando son provocadas por alguna de las técnicas (activas, pasivas o tóxicas), sigue siendo un misterio el fondo psicológico subyacente a su aparición espontánea en ausencia de esas provocaciones. Y lo mismo puede decirse de fenómenos extrapersonales, en los que, mientras no se estudien de manera rigurosa desde la Psicología, permanecerán en el mismo cajón, revueltos, interesantes capacidades poco frecuentes con las supercherías más baratas, contribuyendo a la patologización de algunas personas que poseen aquellas y al engaño de muchas víctimas de estas últimas. Cada vez son más las personas que se interesan por la espiritualidad -también agnóstica y atea (véase en Mayorga, 2017)-desde un planteamiento individual que desborda los límites de la Psicología de la Religión y que necesitan, desde la Psicología, obtener referencia (y a veces, ayuda) para diferenciar las motivaciones y procesos mentalmente sanos de aquellos que obedecen a procesos psicológicamente disfuncionales.

La Psicología Transpersonal y las psicoterapias asociadas a ellas, necesitan refinar sus planteamientos para hacerlos científicamente creíbles (y con eso no se está pretendiendo que sus investigaciones se acomoden exclusivamente a la investigación cuantitativa al uso, propia de las ciencias naturales), necesita rigor en sus constructos y necesita ampliar el diálogo que ya tiene con las instituciones académicas de otros países a nuestro propio ámbito.

Por su parte, los psicólogos que abordan estos temas en el ejercicio de su profesión, necesitan:

a) En primer lugar, no ignorar o minimizar el impacto que los factores religiosos y espirituales ejercen sobre las personas. Al fin y al cabo, para muchos pacientes la psicoterapia lo máximo que puede ofrecer es salud mental y crecimiento personal durante la vida empírica, mientras su religión les ofrece la vida eterna.

b) En segundo lugar, necesitan adquirir una cultura mínima respecto a las diferentes cosmovisiones para poder comprender mejor a la persona que tiene 
delante. No olvidemos que entre los factores que se han demostrado que hacen eficaz una terapia, tal como ha concluido la APA en las investigaciones realizadas por un equipo dirigido por Norcross (2014), está la adaptación del terapeuta a la religiosidad y espiritualidad del paciente, y difícilmente podrá adaptarse desde el analfabetismo tantas veces reinante en este área.

c) En tercer lugar, necesitan adquirir una formación específica para afrontar la dimensión psicológica de los problemas que afloran y que pertenecen a este ámbito. Necesitan interesarse, practicar la sutileza para distinguir los casos en que los procesos que están siguiendo sus pacientes involucran y están condicionados por patologías transpersonales para poder derivarlos o dialogar con personas que les puedan ayudar en la resolución de las mismas, si ellos no están lo suficientemente preparados. O por el contrario, acompañar y estimular la salud mental utilizando los recursos que una sana espiritualidad (o religiosidad) en la que el paciente se encuentra comprometido y posee. En definitiva, necesitan enriquecer sus conocimientos y habilidades a la hora de diagnosticar y ayudar al cambio terapéutico a las personas que a ellos acuden, y que no necesariamente son conscientes de diferenciar, ni capaces de solucionar los problemas, derivados de un funcionamiento psicológicamente insano de sus tendencias trascendentes.

Mientras las universidades sigan sin tomarse en serio estos temas, inhibiéndose -con escasísimas excepciones- de ofrecer formación académica a los futuros profesionales de la psicoterapia, están abandonando a La Suerte para que ella decida si las personas que necesitan ser tratadas y apoyadas en los procesos psicológicos que involucran aspectos transpersonales, van a parar a un profesional preparado, a un profesional sin preparación, o a un pseudoprofesional destructivo. Lo que no resulta coherente, sino prepotente, es achacar a la Psicología Transpersonal falta de rigor académico y científico y no darle oportunidad de tenerlo, abriéndose a los serios estudios y prácticas serias que dentro de este área se están dando. Ni es coherente cortar un trozo del psiquismo del individuo (que, por definición y como la palabra indica, es algo indivisible) dejándolo fuera del estudio y la investigación, por prejuicio o por pereza.

\section{Referencias}

Allport, G.W. (1950). The individual and his religion. MacMillan.

Allport, G. W. y Ross, J. M. (1967). Personal religious orientation and prejudice. Journal Personality Social Psychology, 5(4), 432-443. https://doi.org/10.1037/h0021212

American Psychiatric association. (1994). Manual diagnóstico y estadístico de los trastornos mentales (4ª ed.). Mason.

Aranguren, J. L. (1994). Prólogo. En W. James (ed.), Las variedades de la experiencia religiosa (2a ed., pp. 2-3). Península.

Assagioli, R. (1973). Principi e metodi della Psicosintesi terapeutica. Astrolabio.

Assagioli, R. (1993a). Ser transpersonal. Psicosíntesis para el nacimiento de nuestro Ser real. Gaia Ediciones (Traducción del original en italiano de 1988).

Assagioli, R. (1993b). Autorrealización y perturbaciones psicológicas. En S. Grof y C. Grof (eds.), El poder curativo de las crisis (pp. 58-86). Kairós (Traducción del original en inglés de 1989). 
Beca Infante, J. P. (2008). El cuidado espiritual del enfermo como responsabilidad del profesional de la salud. Ética de los Cuidados, 1(1). http://www.index-f.com/eticuidado/n1/et6734.php

Beit-Hallahmi, B. y Argyle, M. (1997). The psychology of religious behaviour, belief and experience. Routledge. https://doi.org/10.4324/9781315812601

Boadella, D. (1993). Corrientes de vida. Paidos (Traducción del original en inglés de 1987).

Bucke, R. M. (1901). Cosmic Conciousness. A study in the evolution of the human mind. Innes \& Sons. http:// djm.cc/library/Cosmic_Consciousness_edited02.pdf

Capra, F., Steindl-Rast, E. y Matus, T. (1994). Pertenecer al universo. Encuentros entre ciencia y espiritualidad. Edaf (Traducción del original en inglés de 1991).

Cohen, A. B. (2015). Las influencias profundas de la religión en la psicología: moralidad, relaciones intergrupales, autoconceptuación e inculturación. Current Directions in Psychological Science, 24(1), 77-82. https:// www.psychologicalscience.org/uncategorized/las-influencias-profundas-de-la-religion-en-la-psicologiamoralidad-relaciones-intergrupales-autoconceptuacione-inculturacion.html

Cohen, A. B., Malka, A., Rozin, P. y Cherfas, L. (2006). Religion and unforgivable offenses. Journal of Personality, 74, 85-118.

Cornejo Valle, M. y Blázquez Rodríguez, M. (2013). La convergencia de salud y espiritualidad en la sociedad postsecular. Las terapias alternativas y la constitución del ambiente holístico. Revista de Antropología Experimental, 13(2), 11-30.

Delaney, C. (2005). The Spirituality Scale: holistic assessment of the human spiritual dimension. Journal Holistic Nursering, 23(1), 145-167. https://doi.org/10.1177/0898010105276180

Falb, M. D y Pargament K. I. (2014). Religion, Spirituality, and Positive Psychology: Strengthening Well-Being. En J. Teramoto Pedrotti y L. Edwards (eds.), Perspectives on the Intersection of Multiculturalism and Positive Psychology (vol 7, pp. 143-157). https://doi.org/10.1007/978-94-017-8654-6

Ferrer, J. N. (2003). Espiritualidad creativa. Una visión participativa de lo transpersonal. Kairós (Traducción del original en inglés de 2002).

Ferrucci, P. (1981). Crescere. Teoria e pratica della Psicosintesi. Astrolabio.

Flournoy, T. (1903). Les principes de la pychologie religieuse. Kündig. https://archive.org/details/lesprincipesdel00flougoog

Font, J. (1999). Religión, psicopatología y salud mental. Introducción a la psicología de las experiencias religiosas y de las creencias. Paidós.

Frankl, V. (2003). Ante el vacío existencial. Herder (Traducción del original en alemán de 1977).

Freud, S. (2011). Tótem y tabú. Alianza Editorial (Trabajo original publicado en 1912).

Garcés, J. (1985). Present perspectives in Psychology of Religion. Studies in Psychology, 6(23-24), 187-198. https://doi.org/10.1080/02109395.1985.10821442

Garrigou-Lagrange, R. (1957). Las tres edades de la vida interior. Desclée de Brouwer (Traducción del original en francés de 1958).

Gimeno-Bayón, A. (2015) Psicología Transpersonal: una vision personal. Vol. I. Milenio.

Gimeno-Bayón, A. (2019a). Psicopatología y Psicoterapia de las Experiencias Transpersonales. Desclée de Brouwer.

Gimeno-Bayón, A. (2019b). El desarrollo de las tendencias transpersonales: lo Bello, lo Bueno, lo Verdadero y lo Uno. Chiadobooks.

Gimeno-Bayón, A. (2020). Baúl de recursos. Intervenciones desde la Psicoterapia Integradora Humanista. Hakabooks.

Gimeno-Bayón, A. y Rosal, R. (2016). Psicoterapia Integradora Humanista. Manual para el tratamiento de 33 problemas psicosensoriales, cognitivos y emocionales ( $2^{\mathrm{a}}$ ed.). Desclée de Brouwer.

Gimeno-Bayón, A. y Rosal, R. (2017). Manual práctico de Psicoterapia Integradora Humanista. Tratamiento de 69 problemas en los procesos de valoración, decisión y práxicos (2a ed.). Desclée de Brouwer.

González Valdés, T. L. (2004). Las creencias religiosas y su relación con el proceso salud- enfermedad. Revista Electrónica de Psicología Iztacala, 7(2).

Gregoire, J. (1986). Pratiques meditatives orientales et thérapie d'Occident: la meditation parasite. Actualités en Analyse Transactionelle, 10(38), 71-77.

Grof, S. (1988). Psicología Transpersonal. Kairós (Traducción del original en inglés de 1985).

Grof, S. (2015). La Psicología del futuro. Lecciones de la investigación moderna de la consciencia. Los libros de la liebre de marzo (Traducción del original en inglés de 2000).

Grof, C. y Grof, S. (1993a). Introducción. En S. Grof y C. Grof (eds.), El poder curativo de las crisis (pp. 9-19). Kairós (Traducción del original en inglés de 1989).

Grof, C. y Grof, S. (1993b). Emergencia espiritual: la comprensión de las crisis evolutivas. En S. Grof y C. Grof (eds.), El poder curativo de las crisis (pp. 23-57). Kairós (Traducción del original en inglés de 1989). 
Grof, C. y Grof, S. (1993c). La ayuda en casos de emergencia espiritual. En S. Grof y C. Grof (eds.), El poder curativo de las crisis (pp. 243-251). Kairós.

Grof, C. y Grof, S. (1994). Emergencia espiritual: la comprensión y el tratamiento de las crisis transpersonales. En R. Walsh y F. Vaughan (eds.), Trascender el ego (pp. 238-248). Kairós (Traducción del original en inglés de 1980).

Heron, J. (2006). Cosmic Psychology (8 ed.). Endymion Press.

Huxley, A. (1977). La Filosofía Perenne (2 $2^{\mathrm{a}}$ ed.). EDHASA (Traducción del original en inglés de 1945).

James, W. (1994). Las variedades de la experiencia religiosa (2 ed.). Península (Trabajo original publicado en 1902).

Jung, C. J. (2016). Acerca de la psicología de la religión occidental y de la religión oriental. En Obras completas, Vol. 11 (2 $2^{\mathrm{a}}$ ed.). Trotta (Traducción del original en alemán de obras que van desde 1938/1940 a 1950).

King, M. B. y Dein, S. (1998) The spiritual variable in psychiatric research. Psychological Medicine, 28(6), 1259-1262.

Koenig, H. G. (2008). Concerns about Measuring “Spirituality” in Research. The Journal of Nervous and Mental Disease, 196(5), 349-355. https://doi.org/10.1097/NMD.0b013e31816ff796

Koenig, H. G. (2012). Religion, Spirituality, and Health: The Research and Clinical Implications. International Scholarly Research Network ISRN Psychiatry, Article ID 278730. https://doi.org/10.5402/2012/278730

Krippner, S. (1979). Estados alterados de conciencia. En J. White (ed.), La experiencia mística y los estados de conciencia (pp. 23-37). Kairós (Traducción del original en inglés de 1972).

Krishnakumar, S. y Neck, C. (2002). The "what”, "why” and "how” of spirituality in the workplace. Journal of Managerial Psychology, 17(3), 153-164. https://doi.org/10.1108/02683940210423060

Lajoie, D. H. y Shapiro, S. I. (1992). Definitions of transpersonal psychology: The first twenty-three years. Journal of Transpersonal Psychology, 24(1), 79-98. http://www.atpweb.org/jtparchive/trps-24-92-01-079.pdf

Lersch, P. (1971). La estructura de la personalidad (8a ed.). Scientia (Traducción del original en alemán de 1966).

Leuba, J. (1904). La Psychologie Religieuse. L’Année psychologique, 11, 482-493. https://www.persee.fr/doc/ psy_0003-5033_1904_num_11_1_3686

LeShan, L. (1986). Cómo meditar. Guía para el descubrimiento de sí mismo. Kairós (Traducción del original en inglés de 1974).

Lukoff, D., Lu, F. y Turner, R. (1998). From Spiritual Emergency to Spiritual Problem: the Transpersonal Roots of the New DSM-IV Category. Journal of Humanistic Psychology, 38(2), 21-50. https://doi. org/10.1177/00221678980382003

Mankeliunas, M. V. (1957). Introducción a la psicología de la religiosidad. Revista Colombiana de Psicología, 2(2), 153-203. http://dx.doi.org/10.15446/rcp

Maslow, A. (1983). La personalidad creadora. Kairós (Trabajo original publicado en 1971).

Mayorga, F. (2017). Ateísmo sagrado. Hacia una espiritualidad laica. Kairós.

McNamara, W. (1979). La psicología y la tradición mística cristiana. En Ch. Tart (ed.), Psicologías transpersonales/II (pp. 153-190). Paidós.

Nelson, J. E. (2000). Más allá de la dualidad. Integrando el espíritu en nuestra comprensión de la enfermedad mental. Los Libros de la Liebre de Marzo (Traducción del original en inglés de 1994).

Noguera Ferrer, J. (1999). Teoría transpersonal y filosofía perenne. Una evaluación crítica. En M. Almendro (ed.), La consciencia transpersonal (pp. 72-92). Kairós.

Norcross, J. C. (2014). Conclusiones y recomendaciones del Grupo de trabajo interdivisional (Divisiones APA 12 y 29) sobre relaciones de terapia basada en la evidencia. https://societyforpsychotherapy.org/evidencebased-therapy-relationships

Orozco, A. M., Díaz Moreno, M. L. y Herrera Vargas, D. M. (2019). El rol del psicólogo en el abordaje de la dimensión espiritual desde la psicología de la salud: una revisión de la literatura [Trabajo fin de grado Universidad El Bosque (Bogotá)]. https://repositorio.unbosque.edu.co/handle/20.500.12495/2755

Pastor, L. L. (29 agosto 2019). Oír, ver o tocar a un familiar muerto... ¡no es estar loco! La Vanguardia. https:// www.lavanguardia.com/lacontra/20190829/4723964772/oir-ver-o-tocar-a-un-familiar-muerto-no-esestar-loco.html

Quiceno, J. M. y Vinaccia, S. (2009). La salud en el marco de la psicología de la religión y la espiritualidad. Diversitas: Perspectivas en Psicología, 5(2), 321-336.

Reuder, M. E. (1999). A History of Division 36 (Psychology of Religion). En D.A. Dewsbury (ed.), Unification through division: Histories of the Divisions of the American Psychological Association (vol. 4, pp. 91-108). American Psychological Association.

Rosal, R. (2003). ¿Qué nos humaniza? ¿Qué nos deshumaniza? Ensayo de una Ética desde la Psicología. Desclée de Brouwer.

Rosal, R. (2012). Valores éticos o fuerzas que dan sentido a la vida. Qué son y quiénes los vivieron. Milenio.

Rosal, R. y Gimeno-Bayón, A. (2010). La búsqueda de la autenticidad. Reflexión ético-psicológica. Milenio. 
Rychlack (1988). Personalidad y Psicoterapia. Una aproximación a la construcción teórica. Trillas (Traducción del original en inglés de 1973).

Rubia, F. J. (2003). La conexión divina. La experiencia mística y la neurobiología. Crítica.

Salgado, A. (2014). Revisión de estudios empíricos sobre el impacto de la religión, religiosidad y espiritualidad como factores protectores. Propósitos y Representaciones 2(1), 121-159. http://dx.doi.org/10.20511/ pyr2014.v2n1.55.

Salgado-Levano, A. C. (2016). Acerca de la Psicología de la Religión y la Espiritualidad. Revista EDUCA UMCH, 7, 7-27. https://doi.org/10.35756/educaumch.v7i0.2

Sandoval Guzmán, P. E., Rangel Domínguez, N. E., Allende Pérez, S. R. y Ascencio Huertas, L. (2014). Concepto de Espiritualidad del equipo multidisciplinario de una Unidad de Cuidados Paliativos: un estudio descriptivo. Psicooncología, 11(2-3), 333-344. https://doi.org/10.5209/rev_PSIC.2014.v11.n2-3.47392

Scharrón del Río, M. (2010). Supuestos, explicaciones y sistemas de creencias: Ciencia, Religión y Psicología. Revista Puertorriqueña de Psicología, 21, 85-112. https://www.redalyc.org/articulo.oa?id=233218111004

Simkin, H. (2017a). Psicología de la Religión: adaptación y validación de escalas de evaluación psicológica en el contexto argentino. Anuario de Investigaciones, 24, 177-185. http://ppct.caicyt.gov.ar/index.php/anuinv/ article/view/11268/45454575758311

Simkin, H. (2017b). Adaptación al español de la Escala de Espiritualidad y Sentimientos Religiosos (ASPIRES): la trascendencia espiritual en el modelo de los cinco factores. Universitas Psychologica, 16, 2. http://dx.doi. org/10.11144/javeriana.upsy16-2.aeee

Spilka, B., Hood, R. W., Hunsberger, B. y Gorsuch, R. (2003). The psychology of religion: An empirical approach ( $3^{\mathrm{a}}$ ed.). Guilford Press

Starbuck, E. D. (1899). The psychology of religion: an empirical study of the growth of religious consciousness. Charles Scribner's Sons.

Sutich, A. (1969). Some considerations regarding transpersonal psychology. Journal of Transpersonal Psychology, 1(1), 15-16.

Tart, CH. (1979). El universo físico, el universo espiritual y lo paranormal. En Ch. Tart (ed.), Psicologías Transpersonales/I (pp. 113-147). Paidós (Traducción del original en inglés de 1975).

Tobeña, A. (2012). Cerebros ateos y religiosos. Actas Españolas de Psiquiatría 40 (sup.2) 46-51. https://www. actaspsiquiatria.es/repositorio/suplements/14/ESP/14-ESP-571872.pdf

Tsai, J. L., Miao, F. y Seppala, E. (2007). Good feelings in Christianity and Buddhism: Religious differences in Ideal Affect. Personality and Social Psychology Bulletin,33, 409-421.https://doi.org/10.1177/0146167206296107

Vergote, A, (1969). Psicología religiosa (3ª. ed.). Taurus (Traducción del original en francés de 1966).

Vieten, C., Scammell, S., Pilato, R., Ammondson, I., Pargament, K. I. y Lukoff, D. (2013). Spiritual and religious competencies for psychologists. Psychology of Religion and Spirituality, 5(3), 129-144. https://doi. org/10.1037/a0032699

Washburn, M. (1990). Two patterns of transcendence. Journal of Transpersonal Psychology, 3(3), 84-112.

Washburn, M. (1997). El ego y el fundamento dinámico. Kairós (Traducción del original en inglés de 1988).

Washburn, M. (1999). Psicología Transpersonal en una perspectiva psicoanalítica. Los Libros de la Liebre de Marzo (Traducción del original en inglés de 1994).

Watson, P. (2014). La edad de la Nada. El mundo después de la muerte de Dios. Planeta.

Weil, P. (1997). Los límites del ser humano. Los Libros de la Liebre de Marzo (Traducción del original en francés de 1991).

Wilber, K. (1985). La conciencia sin fronteras. Kairós (Traducción del original en inglés de 1979).

Wilber, K. (1991). Los tres ojos del conocimiento. La búsqueda de un nuevo paradigma. Kairós (Traducción del original en inglés de 1982).

Wilber, K. (1994a). Psicología perenne: El espectro de la conciencia. En R. Walsh, R. y F. Vaughan (eds.), Trascender el ego (pp. 49-68). Kairós (Traducción del original en inglés de 1980).

Wilber, K. (1994b). Ojo a ojo: la ciencia y la Psicología Transpersonal. En R. Walsh, R. y F. Vaughan (eds.), Trascender el ego (pp. 293-301). Kairós (Traducción del original en inglés de 1980).

Wilber, K. (1994c). Psicología integral. Kairón (Traducción del original en inglés de 1986).

Wilber, K. (1998). El ojo del espíritu. Una visión integral para un mundo que está enloqueciendo poco a poco. Kairós (Traducción del original en inglés de 1997).

Zohar, D. (1997). ReWiring the Corporate Brain: Using the New Science to Rethink How WeStructurure and Lead Organizations. Berret-Koehler Pub. Inc.

Zohar, D. y Marshall, I. (2001). Inteligencia espiritual. La inteligencia que le permite ser creativo, tener valores y fe. Plaza y Janés (Traducción del original en inglés de 2000). 